\title{
Surficial sediment erodibility from time-series measurements of suspended sediment concentrations: development and validation
}

\author{
Rooni Mathew $^{1,2}$ (D) Johan C. Winterwerp ${ }^{3,4}$
}

Received: 24 July 2016/Accepted: 4 April 2017 /Published online: 21 April 2017

(C) The Author(s) 2017. This article is an open access publication

\begin{abstract}
Numerical models of fine sediment transport depend on different approaches to parameterize the erosion properties of surficial sediment strata. These properties, namely the critical shear stress for erosion and the erosion rate coefficient, are crucial for reproducing the short-term and long-term sediment dynamics of the system. Methods to parameterize these properties involve either specialized laboratory measurements on sediment samples or optimization by model calibration. Based on observations of regular patterns in the variation of suspended sediment concentrations (SSC) over the tidal cycle in a small, narrow estuary, an alternate approach, referred to as the entrainment flux method, for quantifying the erosion properties of surficial bed strata is formulated and applied. The results of this method are shown to be analogous to the erosion data used to formulate the standard linear erosion formulation developed by various authors. The erosion properties inferred from the entrainment flux method are also compared to direct measurements of erodibility on sediment samples from the same site using the Gust microcosm apparatus. The favorable comparison of the two approaches suggests that the entrainment flux method can be used to infer and quantify the erodibility of surficial sediment strata in similar small and narrow estuaries. This method
\end{abstract}

Responsible Editor: Jörg-Olaf Wolff

Rooni Mathew

rmathew@moffattnichol.com

Moffatt \& Nichol, 529 5th Ave, New York, NY 10017, USA

Delft University of Technology, Delft, The Netherlands

3 Department of Civil Engineering and Geosciences, Delft University of Technology, PO Box 5048, 2600 GA Delft, The Netherlands

4 Deltares, Delft, The Netherlands has certain advantages, chiefly its ease of implementation and the fact that it uses SSC time series which would typically be expected to be available for the study of or for model application at a given site. Guidelines for selecting the appropriate dataset for the application of the method are also presented.

Keywords Erodibility · Fluff layer · Critical shear stress · Erosion coefficient $\cdot$ Surficial sediment

\section{Introduction}

Fine sediment (generally defined as clays and silts with particle diameters less than $63 \mu \mathrm{m}$ ) transport in aquatic systems is a subject of considerable study and interest from environmental and commercial perspectives. Fine sediment transport is of consequence to various sediment management problems such as contaminant fate and transport, water quality, siltation of navigation channels, dredged material management, etc. Broadly speaking, the transport processes for fine sediments involve advection and dispersion in the water column and the bed-water exchange processes of erosion and deposition. The former bed-water exchange process represents the mobilization of sediments from the bed followed by entrainment into the water column, and the latter process represents the settling of suspended sediment through the water column followed by deposition onto the bed surface. This paper focuses on the erosion dynamics of fine sediments.

Erosion of fine sediments in the natural environment occurs under the action of shear stresses imposed at the bed-water interface by waves and currents. As such, erosion can be distinguished into four different modes, roughly in increasing order with respect to the magnitude of shear stress responsible and the resulting erosion rate: floc erosion, surface erosion, mass erosion, and liquefaction (Mehta 1991; Winterwerp and 
van Kesteren 2004). Floc erosion refers to the removal of individual sediment flocs from the bed surface. Floc erosion occurs when the mean bed shear stress is at or just below some nominal critical threshold shear stress for surface erosion. Surface erosion is a drained process that occurs when the mean bed shear stress exceeds the mean critical threshold shear stress. This causes a rupture of the physicochemical bonds between flocs at the bed surface, followed by the detachment of flocs from the bed and entrainment into the water column by hydrodynamic drag and lift. In contrast, mass erosion is an undrained process typically associated with much larger bed shear stresses than surface erosion and occurs due to a failure of the sediment matrix along a shear plane in the bed, leading to the erosion of clumps of sediment from the bed. Finally, liquefaction refers to the structural breakdown of the bed sediment matrix, typically under the action of waves, forming a layer of fluid-supported slurry known as fluid mud from which sediment can be entrained into the overlying water column by flow-induced turbulent mixing. The analysis presented in this paper includes data under shear stress regimes characteristic of floc erosion and surface erosion. Therefore, the formulations used to describe these processes and the laboratory methods used to measure and quantify them are reviewed.

Fine sediment erosion was first studied in a systematic manner by Partheniades $(1962,1965)$, also summarized in Partheniades (2010). Using measurements of erosion in flume tests using cohesive sediments from San Francisco Bay, he developed a relationship between the imposed bed shear stress and resulting erosion rate. The data indicated a "hockey stick"-type response, with a shallower slope in the shear stress-erosion rate relationship at low shear stresses (indicative of floc erosion), changing to a steeper slope beyond some threshold shear stress (indicative of surface erosion). However, floc erosion is the subject of some debate in the literature; Piedra-Cueva and Mory (2000) in a targeted experimental study did not find any measurable evidence of floc erosion. More recently, however, Winterwerp et al. (2012), and Van Prooijen and Winterwerp (2010) consider floc erosion to be a consequence of turbulent fluctuations in the mean bed shear stress and the stochastic nature of the critical threshold shear stress for surface erosion. Accordingly, floc erosion occurs when the instantaneous bed shear stress exceeds the local critical threshold shear stress for surface erosion even though the time-averaged bed shear stress may be at or below the spatial-mean critical threshold shear stress for surface erosion. The floc erosion rate was parameterized by these authors as an empirical third-order polynomial function of the turbulence-mean bed shear stress and the critical shear stress for erosion.

In contrast, surface erosion has been well established and studied by various authors; typical numerical sediment transport models include formulations of surface erosion. Using the data indicative of surface erosion as measured by Partheniades (1962, 1965), Kandiah (1974) and Ariathurai and Arulanandan (1978) formulated the erosion rate function as

$E=M\left(\frac{\bar{\tau}_{\mathrm{b}}-\tau_{\mathrm{Cr}}}{\tau_{\mathrm{Cr}}}\right)$ for $\bar{\tau}_{\mathrm{b}}>\tau_{\mathrm{Cr}}$

where $E\left(\mathrm{M} / \mathrm{L}^{2} / \mathrm{T}\right)$ is the erosion rate or mass flux, $\bar{\tau}_{\mathrm{b}}$ $\left(\mathrm{M} / \mathrm{L} / \mathrm{T}^{2}\right)$ is the turbulence mean bed shear stress, $M$ $\left(\mathrm{M} / \mathrm{L}^{2} / \mathrm{T}\right)$ is the erosion rate coefficient, and $\tau_{\mathrm{Cr}}(\mathrm{M} / \mathrm{L} /$ $\mathrm{T}^{2}$ ) is the critical threshold shear stress for erosion. The latter two represent empirical parameters determined from erosion measurements. Equation (1) is also referred to as the standard linear erosion formulation. Note that other authors (Sanford and Halka 1993; Sanford et al. 1991) use Eq. (1) without the normalization by $\tau_{\mathrm{Cr}}$, in which case the units for $M$ change accordingly. Equation (1) is used to model what is referred to as unlimited or type II erosion where $M$ and $\tau_{\mathrm{Cr}}$ do not change with time or depth in the sediment bed (Mehta and Partheniades 1982). However, sediments in nature typically exhibit depth dependence in their erosion properties. For instance, $\tau_{\mathrm{Cr}}$ commonly increases with depth due to the effects of consolidation, thereby limiting the extent of erosion under a given bed shear stress. The erosion behavior under such conditions is referred to as depth-limited or type I erosion (Mehta and Partheniades 1982) and can be formulated as (Parchure and Mehta 1985; Amos et al. 1992)

$E=E_{\mathrm{f}} \exp \left\{\alpha\left(\frac{\bar{\tau}_{\mathrm{b}}-\tau_{\mathrm{Cr}, z}}{\tau_{\mathrm{Cr}, z}}\right)^{\beta}\right\}$

where $E_{\mathrm{f}}\left(\mathrm{M} / \mathrm{L}^{2} / \mathrm{T}\right)$ is referred to as the floc erosion rate; $\alpha$ and $\beta$ are empirical, material-dependent parameters; and $\tau_{\mathrm{Cr}, z}$ is the depth-dependent critical shear stress for erosion. Note that this definition of $E_{\mathrm{f}}$ as the floc erosion rate is different from that of others such as Winterwerp et al. (2012), and Van Prooijen and Winterwerp (2010). Sanford and Maa (2001) subsequently showed that Eqs. (2) and (1) yield identical results simply by allowing $M$ and $\tau_{\mathrm{Cr}}$ in Eq. (1) to vary with depth $z$.

Equation (1) and its variants have been implemented in numerical sediment transport models for numerous applications around the world. Such applications typically rely on either parameterization derived from physical measurements of the erosion properties, achieved using a number of different devices and approaches such as the Gust microcosm (Gust and Mueller 1997), Sedflume (McNeil et al. 1996), carousels (Parchure and Mehta 1985; Amos et al. 1992; Maa et al. 
1993), soil mechanical properties (Winterwerp et al. 2012), etc., or rely on model calibration to suspended sediment concentration (SSC) measurements (Van Kessel et al. 2011; Van Maren et al. 2015). The experimental methods vary in complexity in terms of sample requirements (for example, undisturbed cores versus grab samples), ex situ versus in situ measurements, laboratory equipment (for example, specialized flumes versus conventional soil mechanical measurements), sediment strata sampled (for example, thin layers near the bed surface versus larger depth intervals but deeper in the bed), etc.

Here, we propose an alternative approach for quantifying the erosion properties of surficial bed strata, also referred to in the literature as the fluff layer, in tidal and estuarine systems. This approach uses high-frequency time-series measurements of SSC, water depth, and currents to assess the erosion properties of the fluff layer. As validation of this method, the results are compared against direct measurements of erosion properties on sediment cores measured using the Gust microcosm apparatus. It is also worth noting that the focus of this alternate method is on the development of appropriate parameter values for ultimate use in a numerical sediment transport model. The following sections provide an overview of the study area, the relevance of the fluff layer for sediment dynamics in tidal and estuarine systems, the data used, the analytical procedures involved, followed by a discussion of the results.

\section{Site overview and background}

The data presented in this paper come from the Lower Passaic River (LPR), a tidal estuary that is part of New York Harbor (Fig. 1). The LPR stretches approximately $28 \mathrm{~km}$ long from its mouth in Newark Bay to the head of tide at Dundee Dam. Newark Bay is connected to New York Harbor and Raritan Bay (and the Atlantic Ocean) via the tidal inlets Kill van Kull and Arthur Kill, respectively. The river width ranges from approximately $600 \mathrm{~m}$ at its mouth, declining to about $225 \mathrm{~m}$ at River Mile (RM) 1.4 (about $2.25 \mathrm{~km}$ from the mouth), and about 190 m near RM 4.2 (about $6.75 \mathrm{~km}$ from the mouth); the latter two locations are pertinent to the analysis in this paper. The LPR is the subject of an ongoing environmental cleanup and restoration process, and as part of this process, a number of datasets, including the data presented here, have been collected to support the development and calibration of numerical models of the hydrodynamics, sediment transport, and contaminant fate and transport.

The hydrodynamics and sediment dynamics within the LPR are controlled by the tide, estuarine (gravitational) circulation, and river flow. Semi-diurnal tides (dominant period of $12.42 \mathrm{~h}$, corresponding to the semi-diurnal M2 constituent) entering Newark Bay through the Kill van Kull and Arthur
Kill propagate to the LPR and the head of tide at Dundee Dam, forming an almost standing wave and with maximum currents typically occurring around mid-tide. The tidal range varies from 0.9 to $2.1 \mathrm{~m}$ from neap to spring; the corresponding flow rates due to tidal exchange (based on current measurements at RM 1.4) range approximately 200 to $350 \mathrm{~m}^{3} / \mathrm{s}$ (averaged over the half tidal cycle). In comparison to the flow rates associated with tidal exchange, the annual average river flow over Dundee Dam is only about $34 \mathrm{~m}^{3} / \mathrm{s}$ (a few minor tributaries contribute approximately an additional $15 \%$ freshwater flow). Therefore, river discharge accounts for a relatively small fraction of the total flow in the LPR during low to average flow conditions. Consequently, salinity intrusion occurs during low to average river flow conditions, resulting in a partially mixed water column within the LPR. Salinity intrusion occurs due to the tides and estuarine circulation (defined as the densitydriven circulation resulting in tidally averaged residual currents directed up-estuary in the lower portion of the water column and down-estuary in the upper portion of the water column). The extent of salinity intrusion, as indicated by the location of the salt front, is a function of the tidal phase, river flow, spring-neap cycle, as well as offshore mean water level fluctuations due to set-up and set-down events. The salt front moves down-estuary with the ebb tide, increasing river flow, increasing tidal range (spring tides), and offshore set-down events. Conversely, up-estuary movement of the salt front occurs during conditions of flood tide, decreasing river flow, decreasing tidal range (neap tides), and offshore set-up events. The salt front is also typically co-located with the estuarine turbidity maximum (ETM), a region characterized by relatively high SSC and sediment trapping (Dyer 1997). The hydrodynamics and sediment dynamics during typical tidal and low-average flow conditions in the LPR are also characterized by tidal asymmetry, with higher peak currents and SSC during flood than on ebb. As a result, depth and tidally averaged suspended sediment (SS) fluxes are directed up-estuary at low river flow and down-estuary at high river flow (Chant et al. 2011). Note that the term typical tidal condition is used to refer to tides with expected spring-neap variability in tidal range $(0.9$ to $2.1 \mathrm{~m})$ as opposed to periods affected by storm surges or offshore set-up or set-down events since such events may augment the bed shear stress under such typical tidal conditions.

Figure 2 provides an overview of the SSC dynamics over a $2 \frac{1}{2}$-month period using measurements at two locations near the mouth of the LPR, at RM 1.4 and RM 4.2. The SSC dynamics are shown in relation to the river flow, tidal range (as a proxy for spring-neap variability), and near-bottom salinity (as a proxy for the location of the salt front and the ETM). Instantaneous depth-average SSC ranges from intratidal lows of about $10 \mathrm{mg} / \mathrm{L}$ to highs of about $75 \mathrm{mg} / \mathrm{L}$ at both locations typically, except for higher values co-occurring with the passage of the salt front (and the ETM) at RM 4.2, and 
Fig. 1 Location map of the Lower Passaic River along with the locations of the in situ moorings (squares) and sediment core samples (circles)
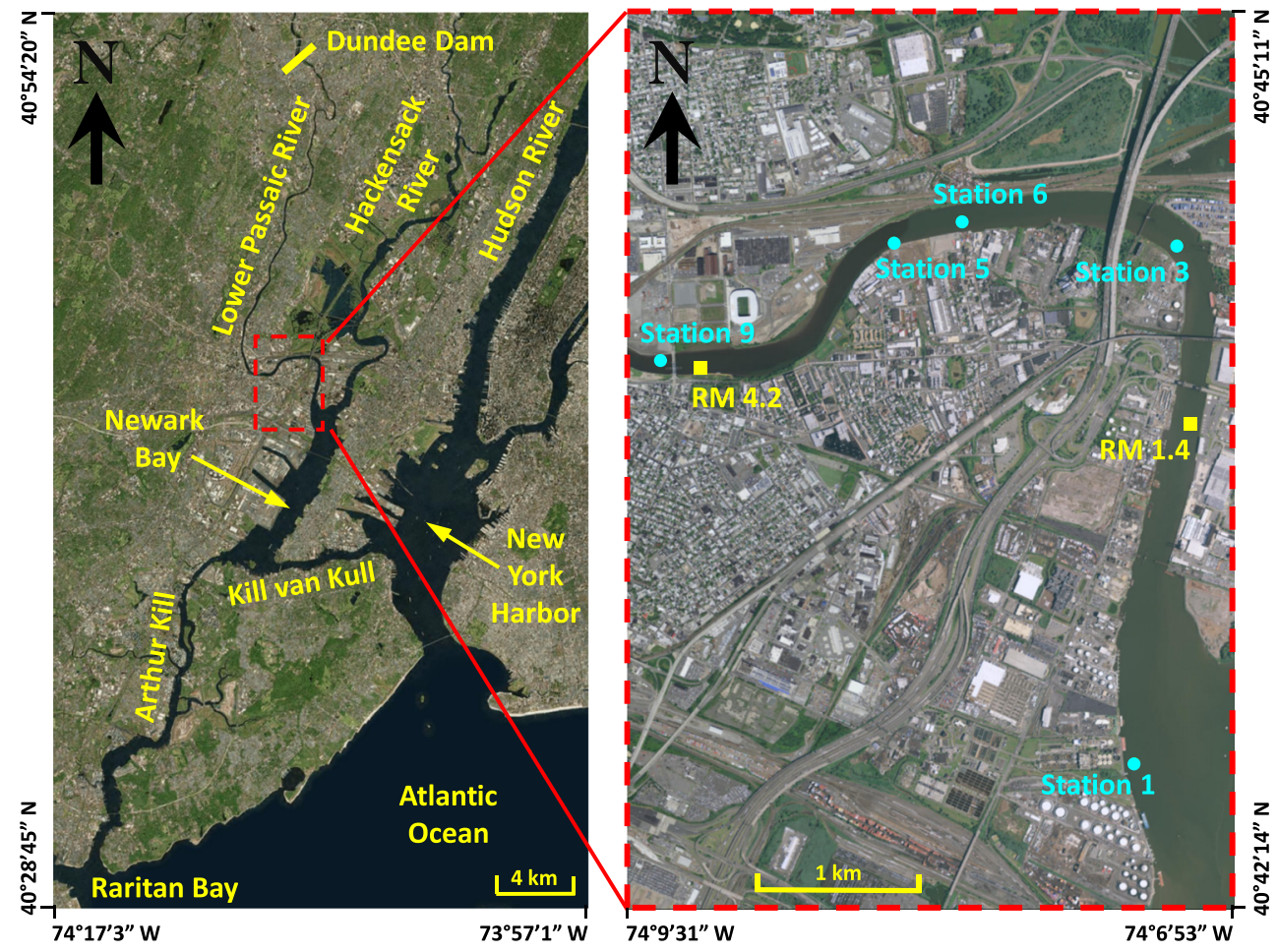

during high-flow periods such as the one in early-mid December. As seen in a 2-day snapshot in Fig. 3 of the tide, depth-average velocity and SSC at RMs 1.4 and 4.2, and the vertical distribution of SSC at RM 4.2 (along with the vertical salinity gradient), the SSC data also show systematic patterns with velocity within the tidal cycle-SSC and velocity magnitudes are positively correlated within the tidal cycle, increasing and decreasing approximately in phase. Nearbottom and depth-average SSC increases as velocity increases, reaching a maximum around the time of maximum velocity and decreasing thereafter to a minimum around slack water, a general pattern true of both ebb and flood tides.
Fig. 2 Time series of a the Dundee Dam discharge and spring-neap variability in tidal range, b near-bottom salinity, $\mathbf{c}$ instantaneous and tidally averaged depth-average SSC at RM 1.4, and $\mathbf{d}$ instantaneous and tidally averaged depth-average $\mathrm{SSC}$ at RM 4.2. Hatched regions indicate 2 days before and after the twice-monthly maximum in tidal range - nominally, spring tide conditions
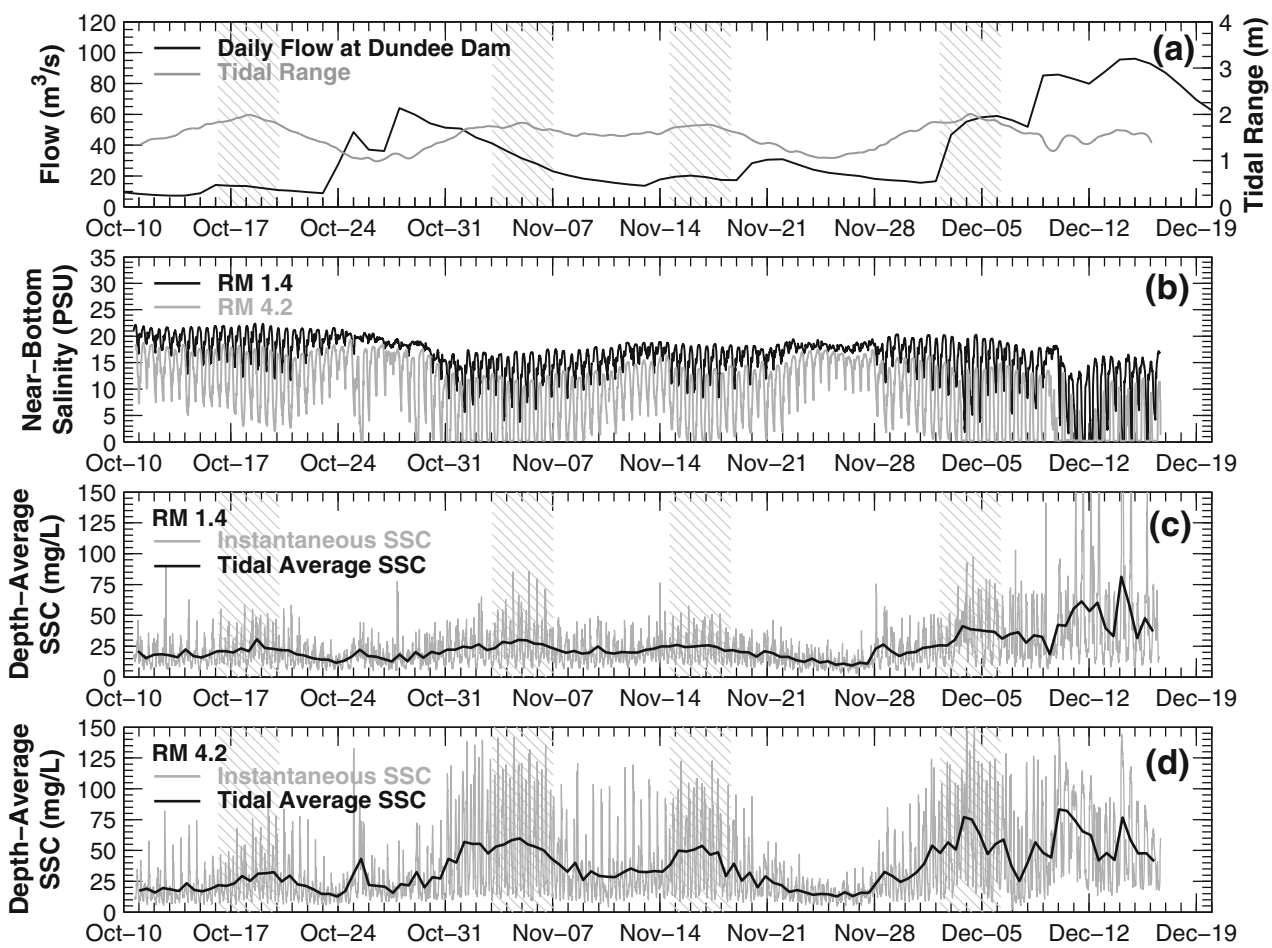
Fig. 3 Time series of a Dundee Dam discharge, water level at RM 1.4 ; $\mathbf{b}$ the depth-average velocity at RMs 1.4 and 4.2; $\mathbf{c}$ the depthaverage SSC at RMs 1.4 and 4.2; and $\mathbf{d}$ the vertical distribution of SSC and salinity gradient at RM 4.2. Hatched regions indicate period of increasing water level
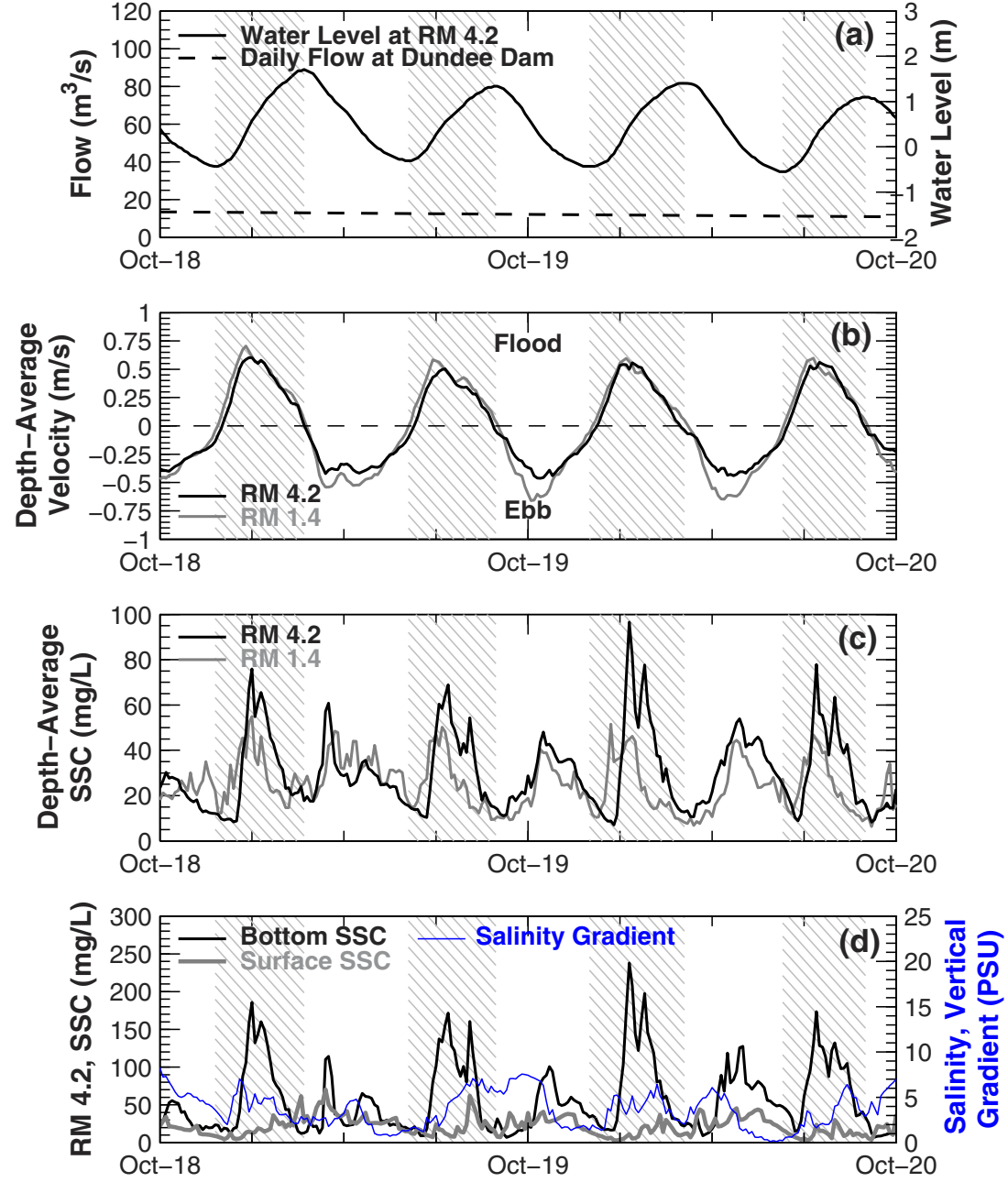

During the period of accelerating velocity, near-bottom SSC increases rapidly with somewhat smaller increase in nearsurface SSC. The vertical gradient in SSC may be influenced by salinity stratification, with stratification (as seen in the time series of the salinity gradient on the bottom panel of Fig. 3) increasing during flood and possibly reducing vertical mixing. The rapid increase in SSC during the accelerating phase of the flood/ebb currents followed by the rapid decrease during the decelerating phase indicates erosion and deposition from/to the sediment bed over tidal time scales. The notion of erosion and deposition within the flood and ebb tides is supported by the fact that the SSC signal is in phase with velocity rather than with the tidal water levels. The correlation with velocity is further explored in Fig. 4 and discussed later in the text. Comparison of the depth-average SSC at RMs 1.4 and 4.2 also shows that both locations attain approximately similar values during slack water, which implies similar SSC over the entire reach between these two locations during slack water. Furthermore, the travel time between RM 1.4 and RM 4.2 is in excess of $3 \mathrm{~h}$, depending on the magnitude of tidal currents which vary over the spring-neap cycle. These

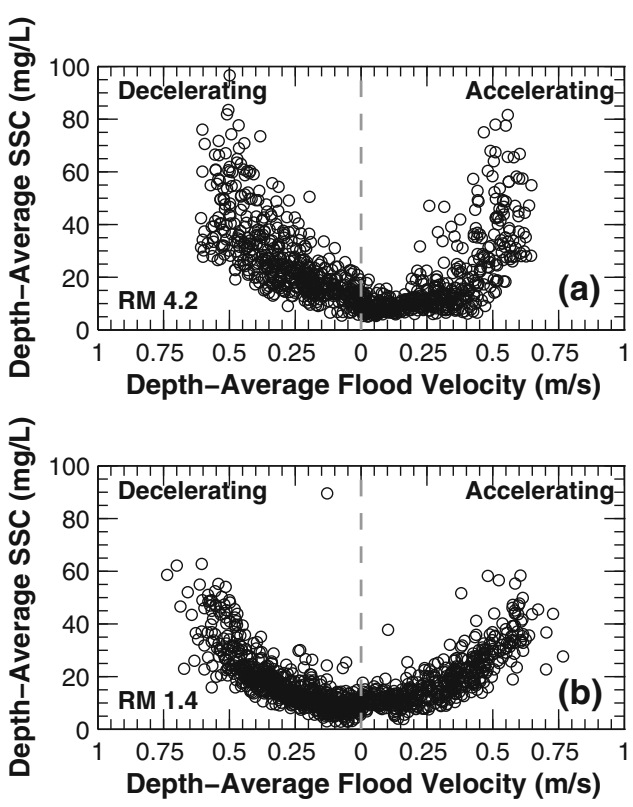

Fig. 4 SSC as a function of depth-average velocity during the flood phase of the tidal cycle at a RM 4.2 and b RM 1.4. Data measured during Oct 11-24, 2009, and Nov 22-27, 2009 
observations suggest that the SSC fluctuations are locally driven, i.e., due to erosion and deposition between RMs 1.4 and 4.2 during the flood and ebb phases of the tide. Focusing on the first half of the flood tide at RM 4.2 (i.e., accelerating flood currents), a period that is the subject of the analysis presented in this paper, the increase in SSC during this period is not due to the advection of a SSC plume from locations down-estuary of RM 1.4. If the advection of such a plume were responsible, SSC would not scale with velocity every tidal cycle, a feature further examined in Fig. 4 and discussed later in the text. Rather, the increase in SSC at RM 4.2 during flood is driven by local erosion in the reach between RMs 1.4 and 4.2 in association with the advection of the eroded sediment up to RM 4.2.

The intra-tidal variability of SSC described above is indicative of the bed-water exchange dynamics, suggesting a small pool of easily erodible sediment, termed a fluff layer, overlying less erodible strata. The fluff layer is comprised of sediments deposited on the bed during slack water and resuspended during the following flood or ebb tide. The excess sediment (when deposition exceeds erosion), if any, in the fluff layer consolidates over time forming less erodible strata. Additional lines of evidence that support the presence of the fluff layer are summarized in the Appendix. Similar sediment dynamics have also been observed in other tidal and estuarine systems (Maa et al. 1998; Van Maren et al. 2015; Van Kessel et al. 2011; El Ganaoui et al. 2004; Wang 2003; Bedford et al. 1987). Using the intra-tidal range in depthaverage SSC of $\sim 10$ to $\sim 75 \mathrm{mg} / \mathrm{L}$ within the salt wedge, with tidally averaged water depth of $6 \mathrm{~m}$, and assuming a dry density of $200 \mathrm{~kg} / \mathrm{m}^{3}$ (for the sediments comprising the fluff layer) results in an estimated fluff layer thickness of about $2 \mathrm{~mm}$. The sediment mass contained within this fluff layer is more or less in equilibrium with the sediments suspended in the water column every tidal cycle. Furthermore, the tidally averaged SSC in Fig. 2c, d also support observations of the relative importance of fluff layer dynamics for sediment transport in the LPR. The tidally averaged SSC varies within a fairly narrow range during October and November (period with river flows less than about $60 \mathrm{~m}^{3} / \mathrm{s}$ ), mainly showing variability in response to the spring-neap cycle, and tending to higher values only at flows greater than about $60 \mathrm{~m}^{3} / \mathrm{s}$ in December. This suggests that the bed-water exchange is dominated by fluff layer dynamics during river flows less than about 1.7 times the annual average flow, i.e., the majority of the time. Therefore the erosion properties of the fluff layer are important for reproducing SSC dynamics and SS fluxes within the system over intra- and inter-tidal time scales during typical tidal conditions and river flows up about 1.7 times the annual average, i.e., the majority of the time.

The concept of a fluff layer has also been implemented in numerical sediment transport model applications at a few sites, most notably by Van Maren et al. (2015) and Van Kessel et al. (2011). However, some relevant information about the fluff layer such as its spatial distribution, composition, structure, and density are currently not very well understood. Nonetheless, theoretical considerations as well as empirical evidence allow for some inference about these features. Review of longitudinal SSC profile surveys in the LPR, as well as SSC data from fixed moorings at RMs 1.4, 4.2, and 6.7, 10.2, and 13.5 (respectively located 10.8, 16.4 , and $21.7 \mathrm{~km}$ from the mouth of the LPR; data not presented here) during typical tidal and low-average flow conditions suggests that fluff layer dynamics are most prominent down-estuary of the salt front and within the ETM zone. Although the SSC time series shows some intra-tidal variability at locations upestuary of the salt front and the ETM zone, the fluctuations are not similar in magnitude as locations further down-estuary. During such low-average river flow conditions, grain size distribution measurements on water samples show composition of nearly $100 \%$ fine sediments entering the study area. Therefore, the fluff layer may predominantly be comprised of fine sediments. Fine sediments in suspension, especially in estuarine settings, are expected to be flocculated, with a range of floc diameters and associated settling velocities (Winterwerp and van Kesteren 2004). As the flocs deposit to the bed, they form a space-filling network structure called a gel. The concentration at which this happens is called the gelling point; it is also known as the structural density (Winterwerp 2002). Based on analysis of unpublished data from a location in Newark Bay close to the mouth of the LPR, the gelling point is estimated to be in excess of $100 \mathrm{~kg} / \mathrm{m}^{3}$. This provides a conservative lower bound on the dry density of the fluff layer; an average dry density of $\sim 500 \mathrm{~kg} /$ $\mathrm{m}^{3}$ measured over the top $15 \mathrm{~cm}$ of the sediment bed between RMs 1.4 and 4.2 provides a conservative upper bound. In summary, even though theoretical considerations and empirical evidence provide some information on the aforementioned properties of the fluff layer, these topics may require more elaborate studies. The remainder of the analysis presented in this manuscript relates only to the erosion properties of the fluff layer.

\section{Materials}

A number of datasets were used in the analysis presented in this paper. The data include time series of SSC, currents, salinity, and water depth measurements, as well as direct measurements of surficial sediment erodibility using a Gust microcosm. These data are described next.

\subsection{SSC and current data}

The SSC and current data presented in this paper come from a moored deployment over a 2-month period (October 10, 2009, to December 16, 2009) at several locations within the LPR. Figure 1 shows the locations of two such moorings relevant to this analysis, at RMs 1.4 and 4.2. The deployment included moored (1) acoustic Doppler current profilers (ADCP), (2) conductivity-temperature-depth (CTD) sensors, and (3) optical 
backscatter (OBS) sensors. The sensors performed in situ measurements at a relatively high frequency, every $12 \mathrm{~min}$, compared to the tidal period of $12.42 \mathrm{~h}$. The ADCPs were deployed in the bottom-mounted, upward-facing configuration and measured the depth profile of flow velocity and echo intensity. The CTD and OBS sensors were deployed $0.9 \mathrm{~m}$ above the bed and $0.9 \mathrm{~m}$ below the water surface for measurements of surface and bottom salinity, temperature, and turbidity along with water depth. The data recorded by the moored instruments were periodically recovered (approximately 1-month intervals), and the instruments serviced and redeployed. Also, water samples were regularly collected at the mooring locations and measured for SSC. These SSC measurements were used to relate the measured turbidity to SSC and acoustic back-scatter (ABS; calculated from echo intensity following the methods of Deines 1999 and Wall et al. 2006) to SSC. The resulting turbidity-SSC and ABS-SSC relationships were applied to the continuous time-series measurements of turbidity and ABS to estimate time series of SSC at the mooring locations. The turbidity-SSC relationship followed a power-law form, with a relatively high $R^{2}=0.84$ (single relationship for all the LPR stations). The ABS-SSC relationships followed a logarithmic form and were more variable, with $R^{2}=0.65$ and $R^{2}=0.87$ at RMs 1.4 and 4.2 , respectively. As an additional check on data quality, the ABS-derived SSC time series were also compared to the turbidity-derived SSC, with the comparison showing reasonably compatible estimates from both sensors. The analysis presented in this paper relies on the ABSestimated SSC time series.

Since the ADCP sensors were mounted on a tripod placed on the sediment bed, a fraction of the water column near the bed was not measured by the ADCP profile measurements. Also, a fraction near the surface of the water column was not measured due to interference and binning artifacts. Both velocity and ABS-estimated SSC in these unmeasured depths are estimated by various extrapolation methods. Velocity in the unmeasured near-surface zone is estimated by assuming that fluid shear decreases linearly from measured values to zero at the surface of the water column. Fluid shear is calculated as

$\tau=\mu \frac{d u}{d z}$

where $\tau=$ fluid shear, $\mu=$ dynamic viscosity of water, $u=$ flow velocity, and $z=$ vertical coordinate $(z=0$ at bottom of the water column). Velocity in the unmeasured near-bottom zone is estimated assuming a log profile:

$u_{z}=\frac{u^{*}}{\kappa} \ln \left(\frac{z}{z_{0}}\right)$

where $u_{*}=$ the bottom friction velocity, $\kappa=0.4=$ the von Karman constant, and $z_{0}=$ bottom roughness length $=0.4 \mathrm{~mm}$, taken from a previous hydrodynamic modeling study of the LPR (HydroQual 2008). SSC in the unmeasured near-bottom and near-surface zones are extrapolated assuming that the vertical SSC profile follows the Rouse distribution (Van Rijn 1984):

$\frac{c}{c_{a}}=\left[\frac{a\left(1-\frac{z}{h}\right)}{z\left(1-\frac{a}{h}\right)}\right]^{\beta}$

where $c=\mathrm{SSC}$ measured at level $z, c_{a}=\mathrm{SSC}$ at reference height $a, h=$ total water depth, and $\beta=$ the Rouse number. $\beta$ was estimated by a least-squares fit of the measured SSC profile. It is also worth noting that other extrapolation methods were tested for both velocity and SSC. However, the overall results presented here did not change appreciably, suggesting that the results are relatively insensitive to the extrapolation technique.

Due to the tidal nature of the system, the measured velocity profiles include a variable number of constant thickness ADCP bins with velocity data over time. In order to assist with subsequent data analysis of the flow field, the velocity profiles are converted from this fixed coordinate system based on depth within the water column, to a sigma $(\sigma)$ coordinate system. The latter coordinate system allows for velocity profiles with a constant number of layers but of variable thickness over time. The $\sigma$ coordinate system is defined as

$\sigma=\frac{z-\eta}{h+\eta}$

where $\eta=$ the instantaneous water level with respect to the reference height $h$. The instantaneous velocity profiles were interpolated to a 20-layer $\sigma$ grid. This transformation of the velocity profile enables some calculations described subsequently that involve the tidal-period averaging of currents in individual layers in the water column.

\subsection{Gust microcosm erosion data}

The direct measurements of erosion properties presented in this paper were performed by CBA (2006) using a Gust microcosm (Gust and Mueller 1997) on undisturbed sediment cores collected from the LPR in May 2005, about 4 years before the mooring deployment described previously. The river flow averaged about $10 \mathrm{~m}^{3} / \mathrm{s}$ during the period of core collection, similar to the river flow over the first 2 weeks of the deployment in Fig. 2. During this period, the salt front (and therefore the ETM) is seen to be located up-estuary of RM 4.2 (as seen in the near-bottom salinity on panel b of Fig. 2). Therefore, the salt front and ETM are estimated to have been located up-estuary of the core locations during the period when the cores were collected. Shallow cores $(\sim 10 \mathrm{~cm})$ were collected from five locations (stations $1,3,5,6$, and 9 as shown in Fig. 1) located within $7 \mathrm{~km}$ from the mouth of the 
LPR. The cores were located in different parts of the river cross section, with average water depths ranging from about 2 to $8 \mathrm{~m}$. Duplicate cores were collected at each location for an assessment of the variability in erodibility. With the exception of station 5 , which was collected about $2 \mathrm{~h}$ after slack water, the remainder of the cores were collected around slack water when the fluff layer would be expected to be at its maximum thickness. The cores were collected using either a piston push corer (at the shallow locations) or by subsampling from a small box corer (at the deeper locations). Each core was extruded until the sediment surface was $10 \mathrm{~cm}$ from the top of the core tube and was then carefully transported by boat to the testing facility located nearby. The erosion measurements were conducted within a few hours of core collection to minimize core disturbance and consolidation.

The cores were subject to erosion measurements using a Gust microcosm apparatus (Gust and Mueller 1997). The Gust microcosm apparatus utilized by CBA (2006) simultaneously measures the erodibility of the duplicate cores collected at each station. The experimental setup consists of two core tubes, with a rotating disc within each core tube, with a layer of continually refreshed water separating the discs from the sediment-water interface. The rotation speed of the disc is used to impose varying shear stresses, with a suction pipe located at the center of the disc to extract the water containing eroded sediments, and for minimizing secondary currents. The shear stress generated by the rotating disc was calibrated in the laboratory using hot-film sensors. The experiment consists of seven 20 min intervals, with increasing shear stress $(0.01$, $0.05,0.1,0.15,0.2,0.3$, and $0.45 \mathrm{~Pa}$ ). The effluent of the system, containing the eroded sediment, was passed through a turbidimeter and collected. The collected effluent water samples were filtered and weighed to determine the exact sediment mass eroded during each step as well as a calibration for the turbidimeter for each step. The calibrated turbidimeter data provides a time series of SSC for each step. The sediment erosion rate is subsequently calculated as the product of the pumping rate and SSC. Further to the discussion above, it is noted that the applied shear stresses are expected to be too low to erode consolidated sediments. The Gust microcosm is therefore considered to measure the erodibility of the fluff layer.

\section{Methods}

\subsection{Entrainment flux}

The analysis for the erosion properties of the fluff layer derives from the following observations from the SSC time-series measurements. Figure 3 shows a 2-day snapshot of the flow at Dundee Dam and the tide at RM 1.4 , the depth-average velocity at RMs 1.4 and 4.2, the depth-average SSC at RMs 1.4 and 4.2, and the vertical distribution of SSC at RM 4.2. This period is associated with below average river flows and typical tidal conditions, i.e., not affected by offshore set-up or set-down events both of which can alter the shear stress regime in the estuary. The shaded area indicates the duration of the flood tide (four flood tides during this 2-day period). Due to flood dominance in tidal currents (and therefore higher range of velocities during flood than on ebb), this analysis is restricted to SSC measured during the flood tide.

The SSC time series shows the cyclic behavior and correlation with velocity described earlier, with concentration increasing as velocity increases and decreasing as velocity decreases. Comparison of the depth-average SSC at RMs 1.4 and 4.2 also shows that concentrations at both locations attain approximately similar values during slack water. For instance, during the first low-water slack period on October 19, SSC at both locations is about $10 \mathrm{mg} / \mathrm{L}$. During the following flood tide, concentrations increase at both locations, to $\sim 50 \mathrm{mg} / \mathrm{L}$ at RM 1.4 and about twice as high $(\sim 100 \mathrm{mg} / \mathrm{L})$ at RM 4.2. During this time period, the salt front and therefore the ETM are located up-estuary of RM 4.2 (at least $4 \mathrm{~km}$ up-estuary of RM 4.2, based on other data not shown here), thereby ruling out the possibility that the additional SSC during the flood tide at RM 4.2 could reflect the up-estuary transport of the ETM. The location of the ETM up-estuary of RM 4.2, and the similarity of the slack-water concentrations at RMs 1.4 and 4.2 during this period leads to the consideration that slack-water concentrations in the entire reach between RM 1.4-4.2 may be similar to the $\sim 10 \mathrm{mg} / \mathrm{L}$ values measured at RM 1.4 and RM 4.2. With this assumption, the increase in SSC measured at RM 4.2 during the following flood tide can only be associated with erosion down-estuary of RM 4.2. Restricted to the duration of accelerating flood velocities, which is also associated with increasing SSC, this increase in SSC at RM 4.2 thus represents gross erosion rather than net erosion (defined as the sum of gross erosion and gross deposition) between RM 1.4 and 4.2 .

The relationship between the flow velocity and SSC can also be seen more clearly in Fig. 4 which includes pairs of the depth-average SSC and velocity at RMs 1.4 and 4.2 during the flood tides between October 11-24, 2009, and November 2227, 2009 (note that these periods cover a full spring-neap cycle). The sediment dynamics during these periods are not affected by (1) presence of the ETM or (2) above-average river flows or (3) offshore set-up/set-down events. The latter two conditions are expected to be associated with aboveaverage flow velocities and shear stresses, whereas considering only periods when the ETM is known to be located upestuary of RM 4.2 ensures consistency with the Gust microcosm erosion measurements since those were performed on sediment cores collected from locations down-estuary of the ETM. The data in Fig. 4 are divided by the phase of flood 
currents (accelerating versus decelerating velocity). On average, the SSC data are seen to follow a predictable pattern. Starting from low water, as flood velocities increase (the right-hand side of both panels), on average, SSC increases, reflecting erosion from the fluff layer. Following peak velocity, as flood velocity decreases (the left-hand side of both panels), on average, SSC decreases, reflecting deposition and thereby reestablishing the fluff layer. The fact that SSC scales as a function of velocity also indicates that the SSC signal reflects erosion from and deposition to the bed within the tidal cycle. Since erosion and deposition during such typical tidal and low-average flow conditions are expected to be dominated by the fluff layer dynamics, this increase in SSC during the accelerating phase of the flood currents is analyzed for an assessment of the erosion properties of the fluff layer. However, since this analysis uses an indirect measurement (SSC) rather than a direct measurement of erosion, the results are presented in terms of the entrainment process rather than erosion. Accordingly, the term entrainment flux is used rather than erosion rate.

Figure 5 shows an idealized conceptualization of the velocity and SSC fluctuations over the tidal cycle (in panels b and c of Fig. 5 respectively) in an Eulerian frame of reference, similar to Fig. 3. Low water $\left(T_{0}\right)$ coincides with slack water $\left(V_{0}\right)$ and also minimum SSC over the tidal cycle $\left(C_{0}\right)$ at RMs 1.4 and 4.2. As the tide starts flooding, flow velocity increases to $V_{1}$ and subsequently $V_{2}$ at time $T_{1}$ and $T_{2}$, respectively; simultaneously, SSC increases to $C_{1}$ and subsequently $C_{2}$. This conceptualization is also depicted in Fig. $5 \mathrm{~d}$ in a Lagrangian frame of reference. Consider three fluid parcels at slack tide $\left(T_{0}\right)$, located at $x$ (RM 4.2), and at $x^{\prime}$ and $x^{\prime \prime}$, some distance down-estuary of RM 4.2. Note that $x^{\prime}$ and $x^{\prime \prime}$ are not fixed in time but a function of the time-variable currents. At $T_{0}$, concentrations in the reach between RM 1.4 and 4.2 are assumed to be uniform $\left(C_{0}\right)$. As the tide starts flooding, at $T_{1}$, the first fluid parcel is transported up-estuary of RM 4.2, and the second fluid parcel moves from $x^{\prime}$ to $x$ (RM 4.2) influenced by some erosion and entrainment over distance $x^{\prime}-x$ and attaining concentration $C_{1}$. At the same time, the third fluid parcel moves from $x^{\prime \prime}$ to $x^{\prime}$ and is also assumed to attain concentration $C_{1}$ due to erosion and entrainment over distance $x^{\prime \prime}-x^{\prime}$. At $T_{2}$, the third fluid parcel is transported up to $x$, associated with concentration $C_{2}$ reflecting the effect of some erosion and entrainment in the time interval from $T_{1}$ to $T_{2}$ and over
Fig. 5 Idealized conceptualization of velocity and SSC fluctuations, and schematization of the entrainment process over the flood tide in the LPR. In Eulerian frame of reference $(\mathbf{a}-\mathbf{c})$ and in Lagrangian frame of reference $(\mathbf{d})$
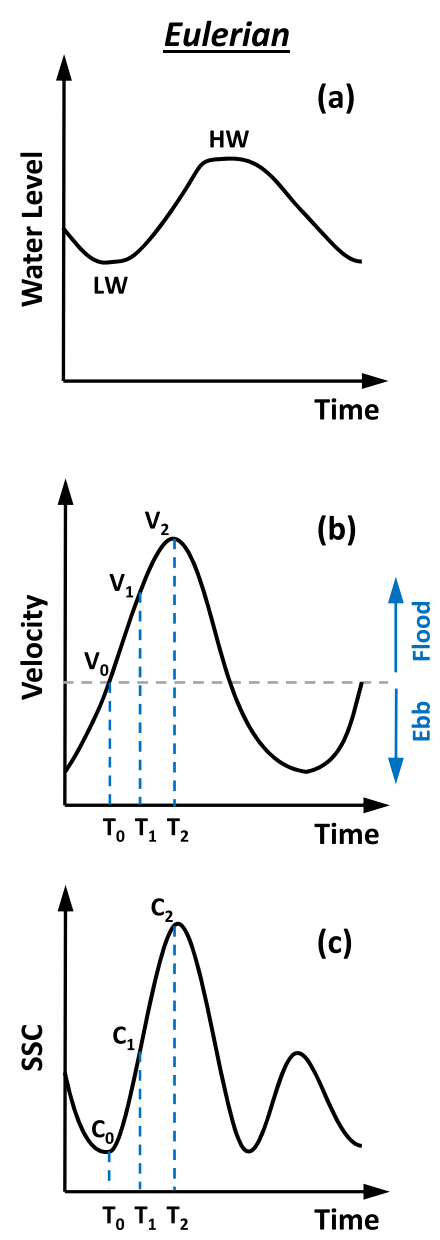

\section{Lagrangian}

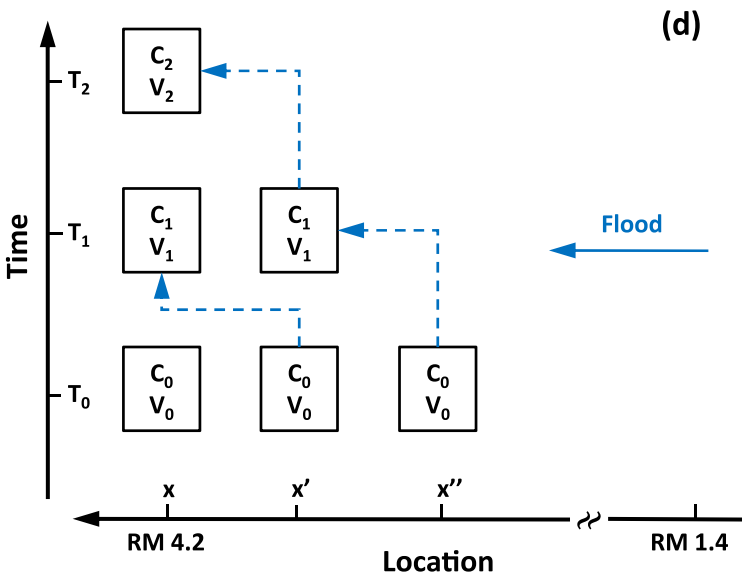

\begin{tabular}{|ll|}
\hline LEGEND & \\
\hline T-Time & LW- Low water \\
V-Velocity & HW - High water \\
C-SSC & 0 - Low-water slack \\
& 1 - Mid-flood \\
& 2 - Mid-flood \\
\hline
\end{tabular}


distance $x^{\prime}-x$. Therefore, the time derivative of the depthaverage SSC at RM 4.2, adjusted for the water depth, is the entrainment flux experienced by given fluid parcel over distance $x^{\prime}-x$ :

$E^{\prime}=\frac{d(\bar{c} h)}{d t}$

where $E^{\prime}=$ entrainment flux $\left(\mathrm{kg} / \mathrm{m}^{2} / \mathrm{s}\right), \bar{c}=$ depth-average $\operatorname{SSC}\left(\mathrm{kg} / \mathrm{m}^{3}\right), t=$ time (s), and $h=$ instantaneous water depth (m). Note that $E^{\prime}$ has the same units as the erosion rate $E$ in Eq. (1). The time interval associated with the application of Eq. (7) derives from the frequency of SSC time-series data (every $12 \mathrm{~min}$ ). As mentioned previously, review of the SSC time series relative to the velocity and salinity time series suggests that the increase in SSC at RM 4.2 is locally driven, i.e., due to erosion between RMs 1.4 and 4.2. Therefore, it is hypothesized that $E^{\prime}$ is a function of the shear stress experienced by given fluid parcel during transit from $x^{\prime}$ to $x$, i.e., the spatial-average Lagrangian shear stress. The entrainment flux is therefore paired with the Lagrangian shear stress and examined for this hypothesis.

The entrainment flux calculation is applied to the time series of SSC measured at RM 4.2 over the same period used for Fig. 4, subject to a few restrictions. The first restriction derives from one of the assumptions of the entrainment flux method that the minimum SSC attained around low-water slack is relatively uniform in the reach between RM 1.4 and RM 4.2. Since the SSC field down-estuary of RM 1.4 is unknown, this assumption implies the need to restrict the entrainment flux analysis to data reflective of erosion only between RMs 1.4 and 4.2, i.e., avoiding data that may reflect SSC dynamics originating from down-estuary of RM 1.4. Another restriction derives from subtle phase differences between the velocity and SSC time series as seen in Fig. 3. Moving from lowwater slack to flood, SSC is typically seen to decline for some time even as flood velocity increases, reaching a minimum some time following initiation of flood currents. For the examples in Fig. 3, this lag is seen to be about 1-2 h; this phenomenon is well known in the literature and is referred to as scour lag (Postma 1961; Dronkers 1985). Subsequently, as flood velocity increases, SSC increases and reaches a maximum after maximum flood velocities are attained. Therefore, the entrainment flux calculation is performed over the duration of minimum to maximum SSC during the flood tide at RM 4.2, a period on the order of $1-2 \mathrm{~h}$ per tidal cycle. These considerations, along with the need to pair the entrainment flux over a given time interval with the spatial-average Lagrangian velocity and shear stress over that time interval (defined as the spatially averaged velocity and shear stress experienced by given fluid parcel over that time interval), necessitates the use of a numerical model to provide a high spatial- and temporal-resolution description of currents in the reach between RMs 1.4 and 4.2 as described in the next section.

\subsection{Numerical model}

The temporally and spatially variable description of currents in the reach between RMs 4.2 and 1.4 are developed using the velocity and water depth measurements to solve the continuity equation for flow rate at a high spatial and temporal resolution. The 1D continuity equation for unsteady open channel flow is written as:

$\frac{d Q}{d x}=-\frac{d A}{d t}$

where, $Q=$ flow rate, $x=$ longitudinal coordinate (along flow direction), and $A=$ cross-sectional area. The availability of high-frequency current measurements at RMs 1.4 and 4.2 paired with water levels, provides the information necessary to solve Eq. (8) at intermediate locations. Limited shipboard instantaneous cross-sectional measurements (not included here) do not suggest significant cross-sectional variations in velocity. Therefore, the calculations are performed for crosssection averaged conditions. Similarly, the calculations are performed using the depth-averaged velocities, with the velocity component due to estuarine circulation zeroed out as a consequence of depth averaging. However, as mentioned subsequently, the estuarine circulation component is included in the post-processing of the results. It should also be noted that although the term 1DH model is used subsequently to describe this application of the 1D continuity equation, this is only a direct solution of the continuity equation for flow-given the inflow rate and the change in storage within given reach, the outflow rate from the reach, and the flow rate at intermediate locations within the reach are solved by numerically integrating Eq. (8) over the reach.

The model application consists of a series of evenly spaced cross sections (approximately every $50 \mathrm{~m}$ ) to represent the reach between RMs 1.4 and 4.2. The bathymetry associated with each cross section is based on a multi-beam bathymetric survey performed in November 2008. The bathymetry data were also used to determine the variation in submerged cross-sectional area (and volume) associated with tidal water level variations for each cross section. The model takes as a boundary condition the depth-average currents measured at RM 1.4 (on flood), and RM 4.2 (on ebb). However, the results are only considered for the period of flood currents which is the period of interest for the entrainment flux analysis described previously. In addition, the variation in water levels measured at RMs 1.4 and 4.2 are also specified as boundary conditions, with the water levels at intermediate locations assumed to vary linearly as a function of distance. Using these inputs and boundary conditions, the model calculates time 
series of the depth-averaged and cross-section averaged flow rates (and therefore velocities) at intermediate locations using Eq. (8).

The model performance is evaluated by comparison with measured velocities at RM 4.2, as shown in Fig. 6a for the depth-average velocities and in Fig. $6 \mathrm{~b}$ for the near-bottom velocities, both for only the periods of flood currents. The nearbottom velocity at RM 4.2 is calculated from the depth-average velocity in the model following Eq. (4). However, the measured near-bottom velocity includes a component due to estuarine circulation (the other components being tidal exchange and river flow; the component due to Stokes drift is zero in this case because the tide behaves as a standing wave in the LPR). In contrast, the model computations only reflect components due to tidal and river flows as mentioned previously. Therefore, the estuarine circulation component is estimated from the data and added to the model computed near-bottom velocity for an appropriate comparison with data. The estuarine circulation component is estimated using the method of tidal averaging (Costa 1989; Siegle et al. 2009; Sommerfield and Wong 2011).

$u_{z, E}=\frac{1}{2 T \Delta z} \int_{0}^{2 T}\left[u_{z} \Delta z-\frac{\Delta z}{h} \int_{0}^{h} u_{z} d z\right] d t$

where $u_{z, E}=$ velocity component associated with estuarine circulation at depth $z, T=$ tidal period (in practice, due to the inequality in the semi-diurnal tides, the tide averaging was performed over two tidal cycles), $\Delta z=$ the instantaneous thickness of $\sigma$ layer at depth $z$, and $u_{z}=$ measured instantaneous velocity at depth $z$. The near-bottom estuarine circulation velocity component (directed up-estuary) thus estimated at RM 4.2 using Eq. (9) averaged about $0.04 \mathrm{~m} / \mathrm{s}$ during October 11-24, 2009, and about $0.07 \mathrm{~m} /$ s during November 22-27, 2009. Similar calculations performed following methods involving signal processing techniques used by others (Lerczak et al. 2006; Chant et al. 2011) yielded similar results for the estuarine circulation velocity component.

Both the comparisons seen in Fig. 6 suggest a reasonably good performance by the model. A few statistical metrics quantifying the model-data comparisons are also included in Fig. 6. These include the root mean square error (RMSE), a measure of the error between the model and data as expressed by:

RMSE $=\sqrt{\frac{\sum\left(u_{\text {data }}-u_{\text {model }}\right)^{2}}{n}}$

where $u_{\text {data }}=$ measured velocity, $u_{\text {model }}=$ model-calculated velocity, and $n=$ number of pairs of model and data. Another metric quantifying the model-data performance is the relative RMSE (\%), defined as the RMSE relative to the data range. The data range is the difference between the minimum and maximum of the measured values. Finally, the correlation coefficient, $R^{2}$, between model and data is also included.

Although the model captures the temporal variability and magnitude of the depth-average velocity several times during this period, it tends to under-predict the peak velocities during other periods. However, the depth-average velocities calculated by the model are of secondary importance; it is mainly used for the travel time and distance calculations associated with estimating the average Lagrangian near-bottom velocities. In
Fig. 6 Comparison of measured and model-calculated a depthaverage flood velocity and $\mathbf{b}$ nearbottom flood velocity at RM 4.2
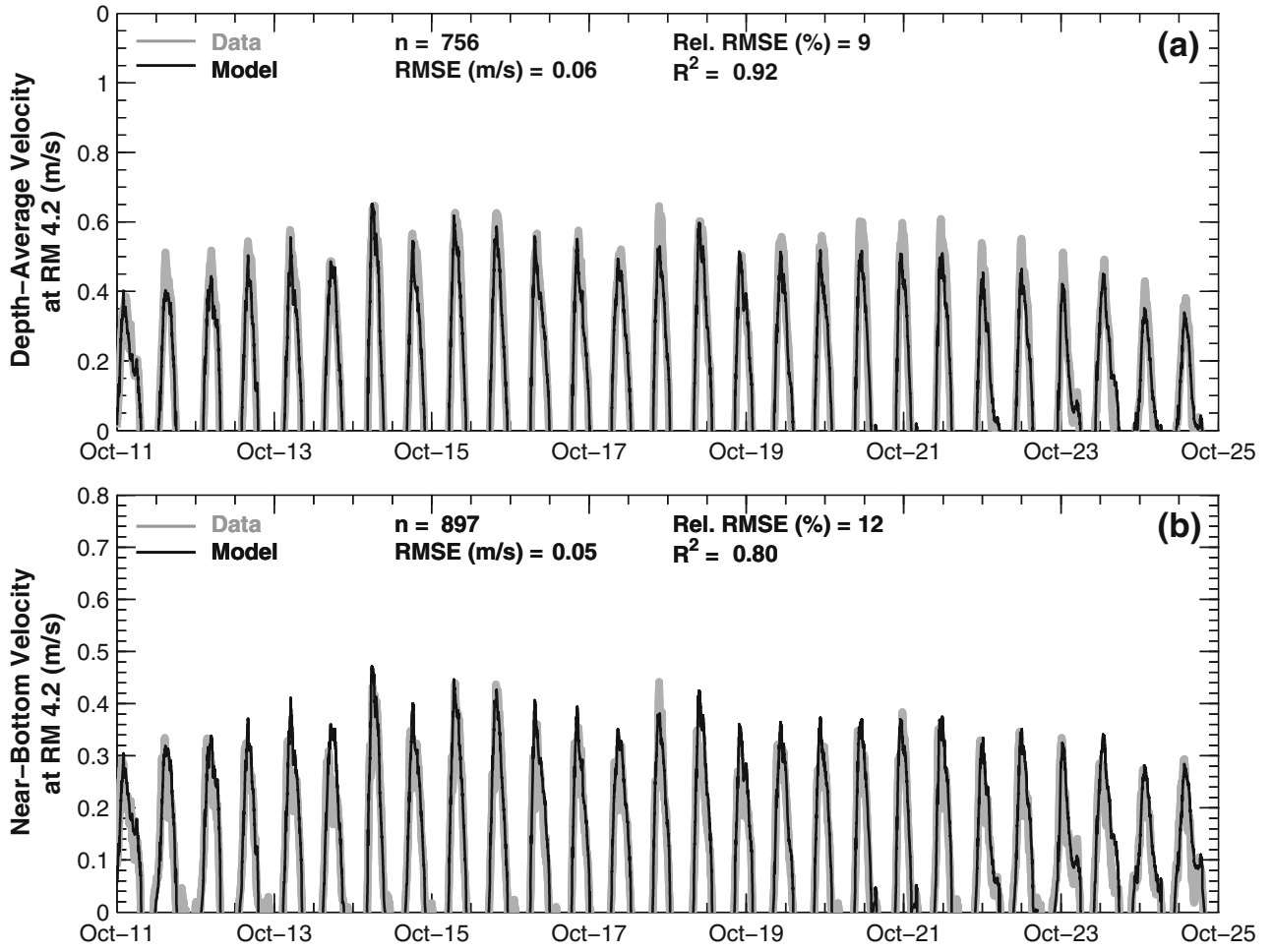
this regard, the near-bottom velocities calculated by the model (and adjusted to include the estuarine circulation component), are more relevant and compare quite well with measured values as seen in Fig. 6b, with both temporal variability and magnitude well reproduced by the model. The statistical assessment of model performance shows reasonable performance - the relative RMSE is 9 and 12\% for depth-average and near-bottom velocity, respectively. Similarly, the correlation coefficient is also relatively robust, at 0.92 and 0.8 for depth-average and near-bottom velocity, respectively. Both the relative RMSE and correlation coefficient are within the bounds of acceptability for such numerical models (Meselhe and Rodrigue 2013). These statistical metrics comparing the model and data, therefore, provide confidence in the performance of the model at RM 4.2 and by extension its ability to reproduce currents in the reach between RM 1.4 and 4.2.

Following standard assumptions for hydrodynamic interactions at the bottom boundary, the effective bottom roughness used in Eq. (4) is assumed to be composed of form-related and grain-related fractions (Van Rijn 1993). The grain-related roughness, calculated as a function of the surficial sediment texture, is considered to generate the skin friction forces relevant to the sediment dynamics of erosion and deposition. Therefore, the calculated near-bottom velocities are used to calculate skin friction as:

$\tau_{\mathrm{SF}}=\rho\left[\frac{u_{\mathrm{b}} \kappa}{\ln \left(\frac{z_{\mathrm{b}}}{z_{\mathrm{OG}}}\right)}\right]^{2}$

where $\tau_{\mathrm{SF}}=$ skin friction, $\rho=$ density of water, $u_{\mathrm{b}}=$ nearbottom velocity calculated by the $1 \mathrm{DH}$ model and adjusted to include the estuarine circulation component, $z_{\mathrm{b}}=$ distance to the mid-point of the bottom-most $\sigma$ layer, and $z_{0 \mathrm{G}}=$ grain roughness height, calculated as

$z_{0 \mathrm{G}}=\frac{k_{s}}{30}=\frac{3 D_{90}}{30}$

where $k_{s}=$ Nikuradse grain roughness (Van Rijn 1993) and $D_{90}=$ particle diameter representing the $90 \%$ cumulative percentile of the sediment grain size distribution, calculated as $140 \mu \mathrm{m}$ using grain size distribution measurements in the sediment bed in the reach between RMs 1.4 and 4.2. The resulting spatial and temporal distributions of depth-average velocity and skin friction are used to calculate the average Lagrangian shear stress to pair with entrainment flux values over the same period.

\subsection{Assumptions of entrainment flux method}

The calculation of the entrainment flux and the pairing with Lagrangian velocities and shear stresses involve a few assumptions and simplifications as listed below:
- The minimum SSC observed around low-water slack is uniform in the reach between RM 1.4 and 4.2.

- The horizontal dispersion of the SSC field is ignored.

- The horizontal shearing of the SSC profile due to flow components associated with estuarine circulation, river flow, and tidal shear is ignored.

- The increase in SSC at RM 4.2 over given duration is associated solely with resuspension over the travel path of that fluid parcel over that duration.

- The effect of local velocity gradients on erosion and deposition between RM 1.4 and 4.2 is not considered. Locally, there may exist areas of higher velocity where larger or more resistant particles may be eroded which may be deposited a short distance away in an area of lower velocity, both within the period of accelerating flood currents and SSC.

- During periods of accelerating flood currents and SSC, gross erosion is the same as net erosion (e.g., we ignore deposition).

- No significant cross-sectional variations exist in currents or SSC.

In addition, the analysis does not distinguish between the various modes of erosion. However, the shear stress regime involved is expected to be characteristic of floc and surface erosion.

\subsection{Gust microcosm erosion data}

The data from the Gust microcosm experiments consists of time series of erosion rate and imposed shear stress. The data was analyzed by CBA (2006) using the erosion formulation of Sanford and Maa (2001). This formulation assumes an exponentially decreasing erosion rate for each shear stress level:

$E_{t}=E_{0} e^{-\lambda t}$

Based on this assumption, the erosion rate time series is extrapolated to determine the total erodible mass for each applied shear stress level. Using the applied shear stress $\left(\tau_{b}\right)$ and total erodible mass, a profile of critical shear stress for erosion is generated. From this profile, the excess shear stress $\left(\tau_{b}-\tau_{C r}\right)$ at the beginning of the step is determined. The initial erosion rate for each step is then divided by the excess shear stress to calculate the erosion rate coefficient, $M$ :

$M=\frac{E_{0}}{\tau_{b}-\tau_{\mathrm{Cr}}}$

The results of the data analysis include the eroded mass (which is a measure of the depth of erosion), critical shear stress for erosion, and erosion rate coefficient for the various shear stress levels for each core. 


\section{Results}

The results of the Gust microcosm experiments are presented first followed by the entrainment fluxes assessed with the $1 \mathrm{DH}$ model and a discussion of the comparison between the two methodologies.

\subsection{Gust microcosm erosion data}

Figure 7 shows the measured depth profile of the critical shear stress for erosion from the Gust microcosm experiments. Each panel includes results for the duplicate cores at each location. The measurements of cumulative eroded mass for each core were converted to an equivalent depth in the bed assuming a dry density of $200 \mathrm{~kg} / \mathrm{m}^{3}$. Note that the exact value assumed for dry density is of secondary importance, it is only used here to transform the results of the erosion experiments, in units of eroded mass per unit area, into depth in the bed which is only used as a more intuitive parameter in the explanation of the erosion results. The resulting depth interval sampled by the Gust microcosm is seen to range only up to a few $\mathrm{mm}$ indicating the shallow pool of sediments eroded during the experiments. The main feature apparent in the data is an order of magnitude increase in the strength of the bed, or the critical shear stress for erosion, within the top 1-2 $\mathrm{mm}$ of the cores. The critical shear stress increases from $0.04 \mathrm{~Pa}$ at the surface of the cores (except station 5, at $0.075 \mathrm{~Pa}$ ) up to $0.4 \mathrm{~Pa}$ within the top $2 \mathrm{~mm}$ of the cores. In the case of stations 5 and 9, the critical shear stress reaches $0.4 \mathrm{~Pa}$ at depths $<1 \mathrm{~mm}$. These critical shear stresses are also within the range of shear stresses experienced in the LPR under typical tidal conditions (this is discussed in more detail in the next section), indicating that this shallow pool of sediments within the top $1-2 \mathrm{~mm}$ of the bed is available for resuspension under typical tidal conditions.

This pattern of a rapid increase in the near-surface strength of the bed and the comparability of critical shear stresses in this near-surface depth interval and the typical tidal shear stresses in the LPR is supportive of the notion of a fluff layer, where the limited residence time and lack of consolidation limit the development of significant bed strength. This depth interval (top 1-2 $\mathrm{mm}$ ) with a rapid increase in measured bed strength also compares well with the thickness of the fluff layer in the LPR presented in Section 2, estimated as $2 \mathrm{~mm}$. This has implications for the development of numerical sediment transport models for estuaries, where typically the hydrograph (on an annual basis) may be dominated by long periods of low-average river flows during which the sediment dynamics are dominated by fluff layer dynamics. During the remainder of the year, the hydrograph may be dominated by high-flow events, resulting in higher shear stresses than usual, as a result of which the bed strata underlying the fluff layer could be exposed and subject to erosion. Therefore, for numerical modeling studies of the long-term sediment transport dynamics in estuaries, it is important to appropriately parameterize the erosion properties of the fluff layer (as well as the underlying, more resistant layers).

Figure 8 shows the depth profile of the erosion rate coefficient $M$ (see Eq. 14) from the Gust microcosm experiments examined in a similar fashion as the critical shear stress for erosion. Although several cores tend to show an increase in the value of $M$ with depth in the bed, others show a variable trend with depth. Both the critical shear stresses as well as the erosion rate coefficients are compared with the results of the entrainment flux analysis in the following section.
Fig. 7 Depth profile of measured critical shear stress for erosion from the Gust microcosm experiments. Solid and dashed lines indicate data for the duplicate cores at each station
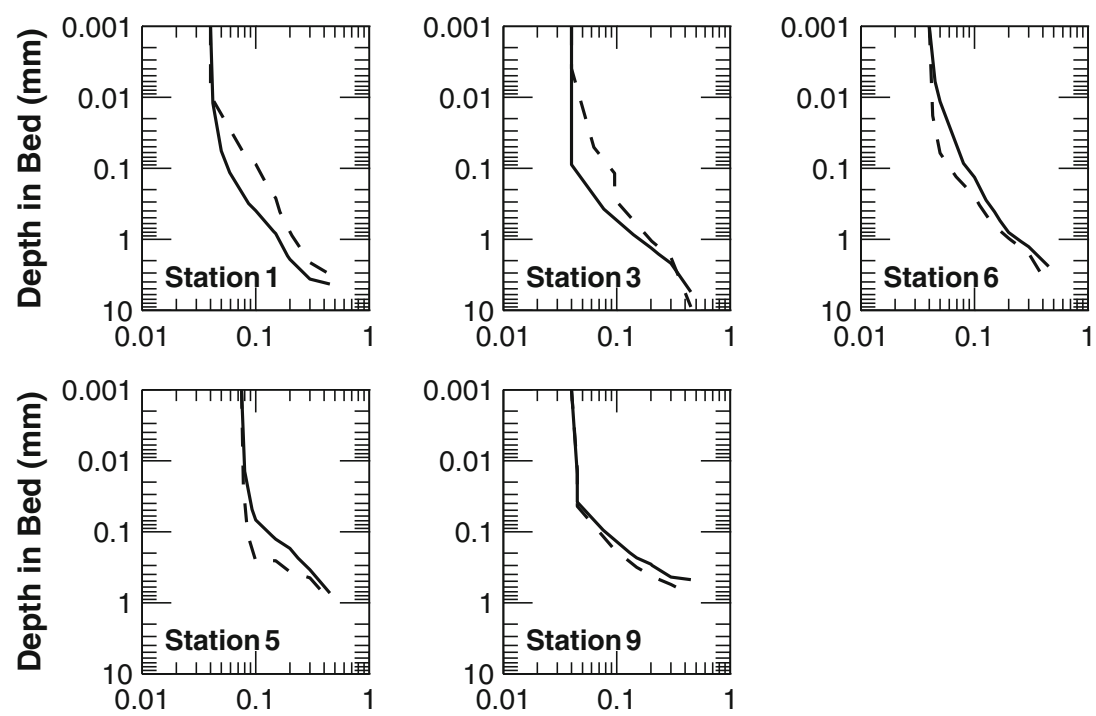

Critical Shear Stress, $\tau_{\mathrm{Cr}}(\mathrm{Pa})$ 
Fig. 8 Depth profile of measured erosion rate coefficient from the Gust microcosm experiments. Solid and dashed lines indicate duplicate cores at each station
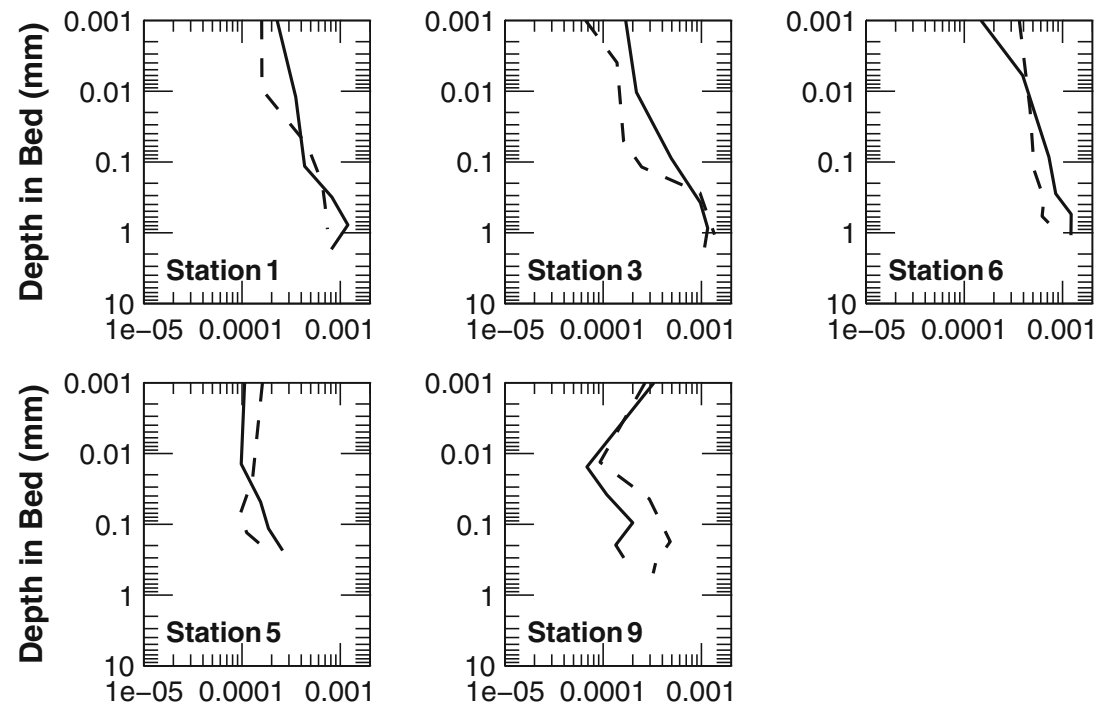

\section{Erosion Rate Coefficient, $\mathrm{M}\left(\mathrm{kg} / \mathrm{m}^{2} / \mathrm{Pa} / \mathrm{s}\right)$}

\subsection{Entrainment flux analysis and validation with Gust microcosm erosion data}

Figure 9 shows the calculated entrainment flux plotted as a function of the average Lagrangian velocity and the average Lagrangian shear stress, both calculated using the results of the $1 \mathrm{DH}$ model. The range of skinfriction-related shear stresses $(<0.425 \mathrm{~Pa})$ in the LPR is seen to be comparable to the range of shear stresses tested in the Gust microcosm experiments (0.01 to $0.45 \mathrm{~Pa}$ ), indicating that the laboratory measurements and the field data provide results over comparable shear stress regimes. Therefore, the erosion process (floc erosion and surface erosion) and resulting parameter estimates from the two methods should also be expected to be comparable.

Since the entrainment flux is calculated from highfrequency SSC measurements, they are susceptible to variability in the SSC time series. The variability in SSC may be real or may also be an artifact of the uncertainty in the ABS-SSC relationship used to derive the SSC time series. This variability manifests itself in the entrainment flux data included in Fig. 9 (as seen in the more than an order of magnitude range in entrainment flux seen at the lower shear stresses), as well as in negative entrainment flux (when SSC at given instant is lower than the SSC at preceding time record). The latter data (instances of negative entrainment flux) is not included here and comprised about $20 \%$ of the dataset. The former manifestation of variability is seen to be more prominent at the lower shear stresses (and lower SSC occurring after slack water) than at higher shear stresses typically during midtide. Nonetheless, the overall trend is a positive relationship between the entrainment flux and the velocity/shear stress. The issue of variability in entrainment flux and therefore uncertainty in the dependency with shear stress is examined in further detail subsequently.
Fig. 9 Calculated entrainment flux relative to the Lagrangian a near-bottom velocity and $\mathbf{b}$ shear stress
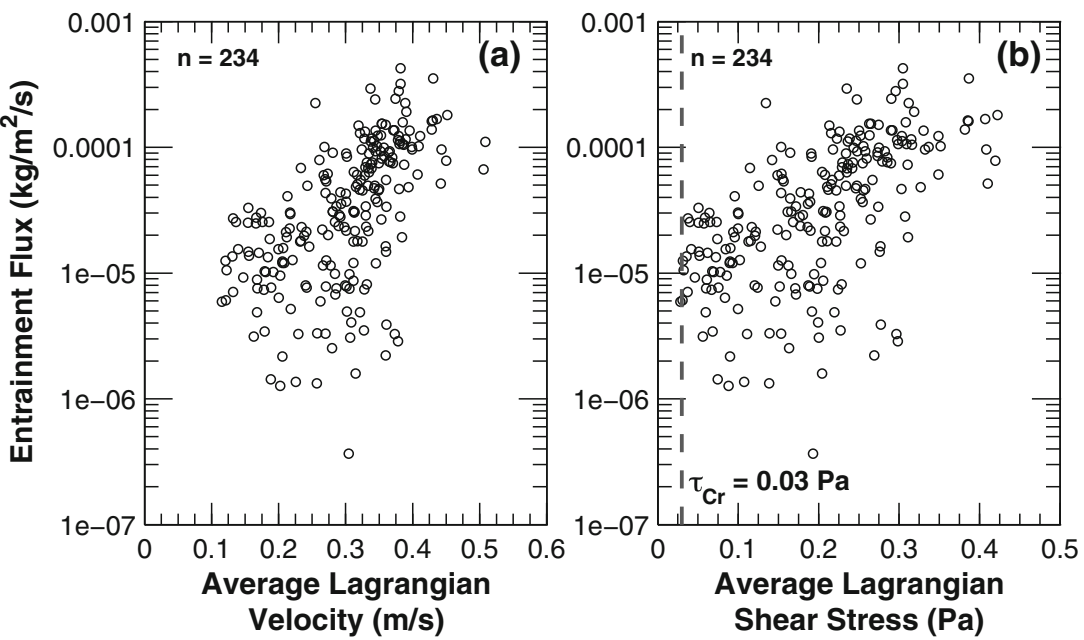
One important erosion property apparent from Fig. 9 is the threshold for initiation of motion or the critical shear stress for erosion; entrainment is noted to occur only at shear stresses greater than $0.03 \mathrm{~Pa}$, which indicates the critical shear stress for the fluff layer. This can be compared to the direct measurements presented in Fig. 7, which show near-surface critical shear stresses starting at $0.04 \mathrm{~Pa}$ and increasing by an order of magnitude within the top 1-2 mm of the bed. Although the entrainment flux analysis does not provide information on the profile of the critical shear stress with depth, the estimated value for critical shear stress of $0.03 \mathrm{~Pa}$ (which would be expected to correspond to the surficial bed strata) is within a factor of two of the surficial critical shear stresses $(0.04 \mathrm{~Pa})$ measured in the Gust microcosm experiments. Besides deviations arising from any mismatch between actual currents (and shear stress) and that predicted by the numerical model, the model results of shear stress in particular are also sensitive to other factors such as the parameterization of the Nikuradse roughness height used to compute skin friction. Furthermore, even direct measurements of the critical shear stress for erosion using different erosion devices do not result in identical parameter values. For instance, Tolhurst et al. (2000) compared measurements of the critical shear stress for erosion of surficial sediments in the Humber estuary (UK) using a Gust microcosm and three other laboratory devices for measuring sediment erodibility. The reported values of the critical shear stress for erosion using the various methods varied by a factor of two. This implies some uncertainty in the results of Gust microcosm experiments in the LPR as well. The difference of $0.01 \mathrm{~Pa}$ between the estimates from the Gust microcosm experiments and the entrainment flux analysis is also relatively small $(2.5 \%)$ compared to the full range of shear stresses under typical tidal and low-average river flow conditions (up to $0.4 \mathrm{~Pa}$ as seen in Fig. 9). Therefore, the results of the entrainment flux method and the Gust microcosm in the LPR are considered comparable for the critical shear stress for erosion of the surficial sediments. This value for the critical shear stress is also comparable to measurements for the fluff layer at other sites $(0.05 \mathrm{~Pa}$ reported by Wang 2003; 0.025-0.05 Pa reported by El Ganaoui et al. 2004; $0.05 \mathrm{~Pa}$ reported by Maa et al. 1998 ; <0.015 $\mathrm{Pa}$ for surficial sediments reported by Sanford and Maa 2001; 0.016 Pa reported by Sanford et al. 1991).

Another trend apparent in Fig. 9 is a relationship between the entrainment flux and the average Lagrangian velocity and shear stress. The individual data points for entrainment flux are somewhat variable, probably reflecting several factors such as natural variability in SSC, uncertainties due to the fact that the SSC time series are based on indirect measurements using $\mathrm{ABS}$ and converted to $\mathrm{SSC}$ using a regression of $\mathrm{ABS}$ and SSC with its accompanying variability, uncertainties due to lack of information on the exact temporal and spatial distribution of velocity and shear stress between RMs 1.4 and
4.2, etc. However, on average, the data suggest a dependency of entrainment flux with velocity and shear stress, with entrainment flux increasing with increasing velocity and shear stress. Functionally, the trend is similar to the relationship inferred from the erosion rate experiments by Partheniades (1962, 1965), and used to formulate Eq. (1) by Kandiah (1974) and Ariathurai and Arulanandan (1978). Therefore, the entrainment flux data is binned in increments of $0.02 \mathrm{~Pa}$ to quantify its relationship with shear stress.

Figure 10 shows the individual entrainment flux data illustrated in Fig. 9b, along with the mean entrainment flux for each of the shear stress bins. The binned entrainment fluxes range over an order of magnitude, from $\sim 1 \times 10^{-5}$ to $\sim 1.5 \times 10^{-4} \mathrm{~kg} / \mathrm{m}^{2} / \mathrm{s}$ over the entire range of typical tidal shear stresses. These values, which reflect the erosion rate of the fluff layer, are more or less comparable to values reported by others (constant $5 \times 10^{-6} \mathrm{~kg} / \mathrm{m}^{2} / \mathrm{s}$ reported by Wang 2003 and $1 \times 10^{-8}-6 \times 10^{-5} \mathrm{~kg} / \mathrm{m}^{2} / \mathrm{s}$ reported by El Ganaoui et al. 2004, both over the same shear stress range; up to $2 \times 10^{-5} \mathrm{~kg} / \mathrm{m}^{2} / \mathrm{s}$ reported by Bedford et al. 1987 over shear stresses up to $0.2 \mathrm{~Pa}$ ). The binned entrainment fluxes are also a function of the Lagrangian shear stress, thus verifying the hypothesis formulated in Section 4.1. The binned entrainment fluxes tend to asymptote to an entrainment flux of about $1.5 \times 10^{-5} \mathrm{~kg} / \mathrm{m}^{2} / \mathrm{s}$ at shear stress less than $0.1 \mathrm{~Pa}$, a trend similar to what has been attributed to floc erosion by Partheniades (1962, 1965). However, since the formulation of the entrainment flux method does not permit distinction between floc erosion and surface erosion, and in the interest of comparing the results of the entrainment flux method to the measurements from the Gust microcosm, no distinction is made between floc erosion and surface erosion.

Working under the assumption that the entrainment flux during the period of accelerating flood currents is an approximation of the gross erosion rate, a linear relationship (also shown in Fig. 10) is developed using the binned entrainment fluxes and following Eq. (1) but without the normalization by

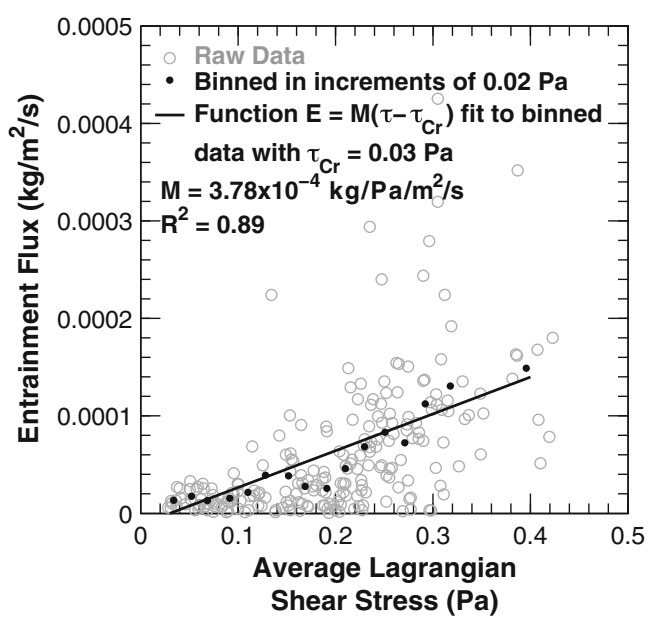

Fig. 10 Entrainment flux as a function of the shear stress 
$\tau_{\mathrm{Cr}}$, and assuming $\tau_{\mathrm{Cr}}=0.03 \mathrm{~Pa}$. The slope of this relationship $\left(=3.78 \times 10^{-4} \mathrm{~kg} / \mathrm{Pa} / \mathrm{m}^{2} / \mathrm{s}\right)$ is comparable to the erosion rate coefficient $M$ presented in Fig. 8 based on the Gust microcosm experiments. The value of $M$ inferred from the entrainment flux analysis can also be compared against the values measured in the Gust microcosm experiments as a validation of the entrainment flux analysis for inferring the erosion properties of surficial sediments. This comparison is shown in Fig. 11 as a probability distribution of measured values for the individual shear stress levels by core (grey squares), and the average erosion rate coefficient by core (black circles) against the erosion rate coefficient estimated from the entrainment flux analysis (solid horizontal line). The value of $M$ inferred from the entrainment flux analysis is similar to the median of the measured values, a reasonable finding since the entrainment flux analysis provides a measure of the spatially integrated erosion properties in the river, whereas the individual cores would be expected to be more variable in response to features such as the shear stress regime at the core locations (which affects the type of particles expected to be present in the bed), shear stress history, location in the cross section which affects the type and magnitude of sediment supply, etc. The erosion rate coefficient estimated from the entrainment flux analysis is also within the overall range of values reported by others for surficial sediment strata $\left(5 \times 10^{-5}\right.$ $1.6 \times 10^{-4} \mathrm{~kg} / \mathrm{Pa} / \mathrm{m}^{2} / \mathrm{s}$ reported by El Ganaoui et al. 2004; $2 \times 10^{-3}-9 \times 10^{-3} \mathrm{~kg} / \mathrm{Pa} / \mathrm{m}^{2} / \mathrm{s}$ reported by Sanford and Maa $2001 ; 8.8 \times 10^{-5} \mathrm{~kg} / \mathrm{Pa} / \mathrm{m}^{2} / \mathrm{s}$ reported by Sanford et al. 1991).

\subsection{Erosion parameters from entrainment flux analysis - variability and uncertainty}

A statistical analysis was performed to examine the impact of the variability inherent in the entrainment flux data on the resulting erosion properties. Similar approaches have been proposed for assessing the effect of data

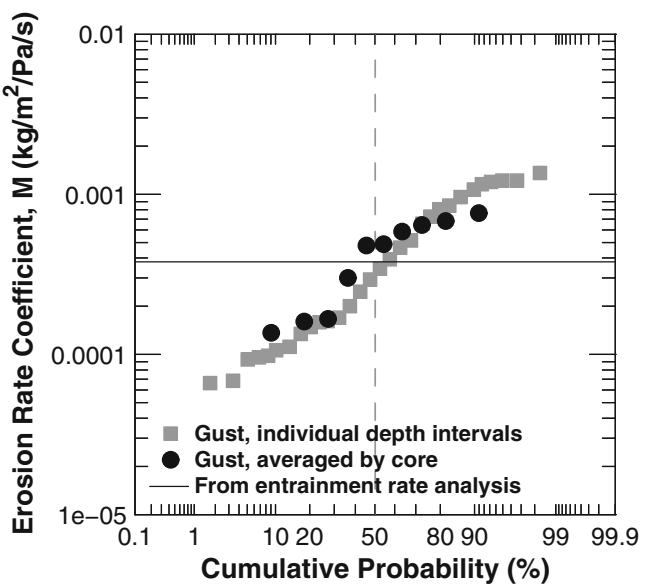

Fig. 11 Probabilistic comparisons of the erosion rate coefficient, $M$, estimated by the entrainment flux analysis (solid horizontal line), and that measured in the Gust microcosm experiments (squares and circles) outliers on regression model parameters (Tsao and Ling 2012). Briefly, the procedure consists of sub-sampling the entrainment flux dataset (pairs of entrainment flux and shear stress) iteratively, fitting the linear erosion function to each of the sub-sampled datasets, and then assessing the variability in the erosion parameters calculated for the sub-sampled datasets. The overall entrainment flux dataset shown in Fig. 9 and Fig. 10 consists of data from October 11-24 and November 22-27, 2009. This period covers a full spring-neap cycle and comprises 36 separate flood tides. The data were first segregated into low, medium, and high tidal range datasets, with 12 tides in each group. The sub-sampling was performed by randomly selecting three separate tides from each of these tidal range groups (to characterize the full range of shear stresses over the spring-neap cycle), for a total of nine tides per sub-sample. The critical shear stress for erosion was defined as the minimum shear stress within each sub-sampled dataset, and a linear erosion function developed for each subsample following the procedure described previously in association with Fig. 10.

The sub-sampling and parameter estimation procedure was implemented a large number of times $(n=10,000)$ to estimate the variability in erosion parameters. Figure 12 shows the results of this exercise. The individual values of the erosion rate coefficient and the critical shear stress for erosion calculated for the sub-sampled data are shown as a cumulative probability distribution (squares). The parameter estimates developed from the entire dataset (in Figs. 9 and 10) are included with a solid horizontal line. The parameter estimates for both the erosion rate coefficient and the critical shear stress for erosion from the entire dataset are seen to be very similar to the median value from the sub-sampled data. Furthermore, about $70 \%$ of the time, the sub-sampled data indicate a critical shear stress for erosion about the same as estimated from the entire dataset $(0.03 \mathrm{~Pa})$. Similarly, the entire range of values for the erosion rate coefficient in the sub-sampled data is within $+/-$ a factor of two of the value estimated from the entire dataset. Even though the individual measurements of entrainment flux shown in Fig. 9 tend to be variable by an order of magnitude or more, this does not translate to similar variability in the erosion parameter estimates. The erosion rate coefficient varies by only about a factor of three from the lower to upper end of the distribution based on sub-sampled data. Similarly, the distribution of the critical shear stress for erosion in the sub-sampled data tends to be relatively constant over the vast majority of the data, deviating from $0.03 \mathrm{~Pa}$ appreciably (by more than $50 \%$ ) only within the upper 10th percentile. The sub-sampling of the overall dataset allows for an assessment of the potential variability in the estimates of the erosion rate coefficient and the critical shear stress for erosion. These comparisons suggest that although the entrainment flux data from individual tidal cycles may be somewhat variable, when 
Fig. 12 Probabilistic comparisons of parameter estimates from entrainment flux analysis on the entire dataset (solid horizontal line) against population estimates from subsampling the entrainment flux dataset (squares). Comparisons of the critical shear stress for erosion (a) and the erosion rate coefficient (b)
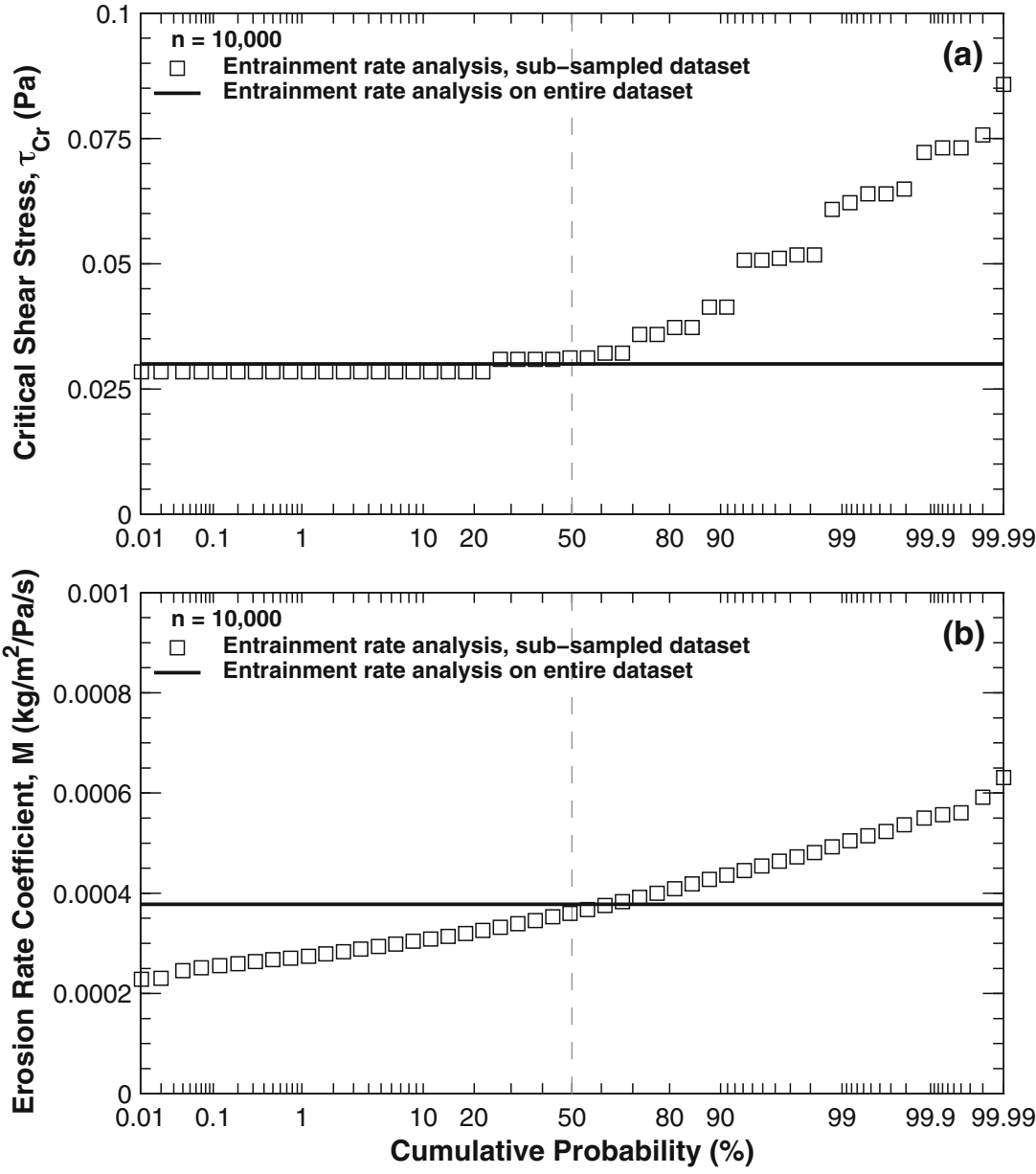

aggregated over several tidal cycles, the entrainment flux method tends to produce erosion parameter estimates that are relatively robust.

\section{Discussion}

Estuarine sediment transport dynamics reflect a balance between tidal and fluvial transport processes. Tidal processes result in SSC dynamics that follow the tidal currents, often with erosion and deposition over tidal time scales, resulting in the creation (by deposition) and destruction (by erosion) of a thin layer of easily erodible sediments termed the fluff layer overlying more consolidated and less erodible strata. During episodic high river flow periods, the SSC dynamics are altered such that fluvial processes become more relevant due to the higher flow velocities and shear stresses generated under such conditions. During such conditions, the fluff layer dynamics become of secondary importance, and the less erodible strata underlying the fluff layer may be exposed, and become more relevant for sediment dynamics. These flow-dependent dynamics are apparent in the tidally averaged SSC time series described previously in association with Fig. 2.
In a system such as the LPR, where the hydrograph is dominated by long periods of below-average to average flows interrupted by episodic above-average periods, the SSC dynamics can be said to be dominated by tidal processes the majority of the time. Therefore, the erosion properties of the fluff layer are of primary importance in reproducing the SSC dynamics the majority of the time and particularly relevant for the up-estuary transport of fine sediments during typical tidal conditions by estuarine circulation and tidal asymmetries. In addition to the SSC fluctuations, the SS dynamics also influence the phenomenon of ETM formation, as well as the patterns of deposition during such periods. Three approaches that have been reported in the literature for parameterizing the erosion properties of the fluff layer include (1) direct measurements using an apparatus such as the Gust microcosm, Sea Carousel, etc. (Gust and Mueller 1997; Parchure and Mehta 1985; Amos et al. 1992; Maa et al. 1993), (2) model calibration to SSC measurements (Van Kessel et al. 2011; Van Maren et al. 2015), and (3) using field measurements (Wang 2003; Sanford et al. 1991; deVries 1992). The entrainment flux method is an additional approach using field measurements that can serve as a useful alternative in situations where direct measurements of erosion may be difficult or cost-prohibitive. 
For instance, even though the Gust microcosm experiments can be performed ex situ, the experimental apparatus still needs to be set up on site in order to minimize transport of the sediment cores and the potential for disturbance of the cores during transit. Furthermore, given the extremely low shear stresses and depth intervals involved in the erosion of the fluff layer, the erosion of the fluff layer is somewhat difficult to measure. Alternatively, the entrainment flux method can also serve to reduce the number of model calibration parameters in cases where the erosion properties of the fluff layer are aimed to be determined by calibration of a numerical model. Such calibration exercises typically involve a large number of iterative simulations to optimize the calibration parameters (the critical shear stress for erosion and the erosion rate coefficient for the fluff layer).

The entrainment flux method derives from certain systematic patterns in the SSC signal in relation to the tidal currents. As described in connection with Fig. 3, the increase in SSC within the flood tide is restricted to about $1-2 \mathrm{~h}$ (the erosion is preceded by a duration of $\sim 1 \mathrm{~h}$ associated with scour lag). This duration of $\sim 1-2 \mathrm{~h}$ with increasing SSC (from minimum to maximum SSC within the tidal cycle) typically extends from somewhat low velocities following slack water to past peak flood velocities. In other words, SSC scales as a function of the tidal velocity. This is a signal consistent with erosion and entrainment from the fluff layer rather than the advection of a SSC plume from elsewhere within the estuary. Subsequently, SSC decreases due to deposition. The increase in SSC during this period of up to $\sim 1-2 \mathrm{~h}$ is used to calculate the entrainment flux and is shown to be a function of the shear stress regime and used to infer the erosion properties of the fluff layer. These inferred erosion properties are also shown to be comparable to direct measurements using the Gust microcosm apparatus. The similarity of the results of the Gust microcosm experiments (on average) and the results of the entrainment flux analysis is an important finding because the former is based on direct measurements of erosion properties, whereas the latter is inferred from indirect measurements of SSC. This provides a validation of the method and the results of the entrainment flux analysis. This is the more remarkable because the two datasets were collected more than 4 years apart, with several major storm events associated with significant river flows in the intervening period which would be expected to alter the sediment dynamics in the river, albeit over shortterm time scales. The fact that erosion properties inferred from the analysis of measured SSC time series are consistent with the Gust microcosm data also suggests that the direct measurements of erosion parameters are consistent with the SS dynamics in the LPR under low-average flow and typical tidal conditions. This comparison also implies that the fluff layer maintains its erosion properties over long periods of time despite the fact that the fluff layer is reformed every tidal cycle, i.e., is continually renewed. This implies that the erosion properties of the fluff layer are an inherent physical property of the system, and a constant feature at least over the 4-year time period examined here. This validation also suggests that the results of the entrainment flux analysis can be used to infer the average erosion properties of surficial sediment strata in such systems characterized by regular, periodic fluctuations in SSC.

Similar procedures to infer erosion properties from indirect measurements, i.e., SSC time series have been applied by others (Sanford et al. 1991; deVries 1992). However, these studies were limited in scope, with data from a limited number of tidal cycles, and using the local shear stress rather than the Lagrangian shear stress. The analysis presented here uses data over a larger period of time and covers the full range of spring to neap shear stresses expected in the estuary during typical tidal and flow conditions. In addition, the comparison with the results of the Gust microcosm experiments provides a validation of the entrainment flux method for inferring the erosion properties of the fluff layer. However, unlike the Gust microcosm experiments, the entrainment flux method does not provide information on the depth profile of the critical shear stress for erosion. As seen in Fig. 7, the critical shear stress for erosion may increase by nearly an order of magnitude within the top few millimeters of the sediment bed, a depth interval that corresponds to the thickness of the fluff layer. However, typical state of practice numerical sediment transport model applications do not resolve the vertical structure in the bed at such a high resolution; the typical resolution in the bed is on the order of millimeters to centimeters, with a unique value for the critical shear stress for erosion associated with a given bed layer. From this perspective, it is more important to resolve the overall depth profile of the critical shear stress at length scales relevant to the numerical model. The results of the entrainment flux method provide a starting point to parameterize the critical shear stress of the fluff layer within the numerical model. Empirical methods such as Sedflume (McNeil et al. 1996) or based on soil mechanical properties (Winterwerp et al. 2012) can be used to determine the critical shear stress of the more consolidated bed underneath the fluff layer.

The validation of the entrainment flux method also suggests that this method can be used for inferring the erosion properties of similar systems elsewhere. The main advantages of this method are that it is relatively easy and straightforward to implement, and it makes use of SSC time series that may be collected and required for purposes such as model calibration, or developing a data-based understanding of the sediment dynamics in given system. However, the SSC data needs to be carefully reviewed and screened in order to select an appropriate dataset for analysis. Since the entrainment flux method is constructed to infer the erosion properties of the fluff layer, which is the layer responsible for the bed-water exchange dynamics under typical tidal and low-average river-flow conditions, the SSC time series should be screened to filter out 
periods of elevated river flows, or off-shore set-up and setdown events, all of which can result in elevated SSC as a consequence of above-average shear stresses and therefore erosion potentially extending to sediment strata below the fluff layer. Finally, given the inherent variability associated with such observations in natural systems, an appropriately large dataset (e.g., data from several tides rather than a single tide) should be considered for a truly representative estimate of the erosion properties of the fluff layer.

\section{Conclusions}

An alternate approach, referred to as the entrainment flux method, for quantifying the erodibility of fine sediments from the surficial sediment strata in a small estuary is formulated and applied. The results of this method are shown to be analogous to the erosion rate data used to fit the well-known and widely applied standard linear erosion formulation. The method helps to infer the critical shear stress for erosion and the erosion rate coefficient of the surficial sediment strata, both of which are important inputs in the application of numerical sediment transport models in estuaries and tidal systems. The erosion properties inferred from this approach are also compared to direct measurements of erodibility using the Gust microcosm apparatus. The favorable comparison of the two methods suggests that the entrainment flux method can be used to infer and quantify the erodibility of the surficial sediment strata in such systems. The entrainment flux method has certain advantages, chiefly its ease of implementation and the fact that it uses SSC time series which would typically be expected to be available for the study of or for the model application at a given site. Guidelines for selecting the appropriate dataset for the application of the method are also developed. The expected applications of this method are in relatively narrow estuaries without significant lateral (across the cross section) variations in currents or SSC, unless if suitable information on lateral variability is available.

Acknowledgments The data used in this analysis was collected as part of the Remedial Investigation of the Lower Passaic River Study Area being conducted by the Cooperating Parties Group under supervision by the United States Environmental Protection Agency. We would also like to thank two anonymous reviewers for their valuable comments.

\section{Appendix}

In the analyses presented in this paper, we introduce the behavior of a layer of easily erodible sediments (referred to as the fluff layer) on the river bed. There are several lines of evidence, some direct and others indirect, and some more definitive than others, to support the presence of such a fluff layer in the LPR. Two of these arguments, namely the intratidal fluctuations in SSC and the Gust microcosm measurements, presented previously are also summarized here for completeness. The various lines of evidence include:

- SSC data (indirect evidence)-The intra-tidal variability in SSC presented in Fig. 3 indicates erosion and deposition to the bed within the half tide. This pattern of successive erosion and deposition at such time scales implies a pool of surficial sediments, limited in consolidation by residence time in the bed $(\sim 6 \mathrm{~h})$, and therefore easily erodible.

- Gust microcosm measurements (direct evidence)Measurements of the critical shear stress for erosion from the Gust microcosm experiments presented in Fig. 7 show erodible surficial sediments over the range of bed shear stresses in the LPR during low to moderate river flows and typical tidal conditions (the $x$-axis in Fig. 9b provides an indication of the range of bed shear stresses in the LPR under such conditions). Furthermore, the cores tested in the Gust microcosm experiments were collected around slack water when the fluff layer is expected to be at its maximum thickness. Furthermore, the depth of erosion during the experiments is quite limited, and estimated to be only up to a few $\mathrm{mm}$. The shallow depth of erosion in combination with the fact that the bed shear stresses imposed during the Gust microcosm experiments are representative of the bed shear stresses in the LPR during low to moderate river flows and typical tidal conditions suggests that the sediments eroded during the Gust microcosm experiments likely originated from the fluff layer.

- Sedflume measurements (direct evidence) -Empirical observations of the erosion of surficial sediments during a Sedflume study in 2012 (Sea Engineering 2013) to measure the erosion properties of sub-surface sediments included visual observations of a thin surficial layer of easily erodible sediment. The Sedflume experimental protocol consisted of running a sequence of increasing bed shear stresses (starting from $0.1 \mathrm{~Pa}$ ) on undisturbed cores collected from various locations in Newark Bay and measuring the corresponding depth of erosion at each shear stress level. In several of the cores, a thin layer of loosely packed material was noted; this material typically eroded at the lowest shear stress run in the experiment $(0.1 \mathrm{~Pa})$. The bed thickness associated with this surficial layer was also smaller than the vertical resolution of the Sedflume device $(0.5 \mathrm{~cm})$. This provides another empirical line of evidence for the presence and easily erodible nature of the fluff layer.

- SPI data (indirect evidence)-High-resolution images of the in situ bed substrate and sediment-water interface were collected during a sediment profile imaging (SPI) survey at several locations within the LPR (Germano, and 
Associates, Inc 2005). The SPI apparatus consists of a camera system housed within a wedge-shaped prism with a transparent faceplate. The faceplate is oriented vertically as the assembly is lowered into the sediment bed, thus allowing photographic imaging of the sediment-water interface and bed profile. The assembly is also held level through this process, allowing for an evaluation of sediment stratigraphy and bottom roughness amongst other properties relevant from biological and geochemical perspectives. Figure 13 includes one of the images captured from the SPI survey, for a location at the mouth of the LPR (and in the vicinity of station 1 shown in Fig. 1). This image was taken at high water when conceptually the fluff layer is expected to be at its maximum thickness. Distinct layers of different sediment types are apparent in this image, with a dark brown sand layer at $\sim 5 \mathrm{~cm}$ depth and a thin dark brown layer with somewhat coarse sediment apparent about 2-3 mm below the sediment-water interface. The sediments above this coarse sediment layer, i.e., within the top 2-3 $\mathrm{mm}$ of the bed, appear to be somewhat finer in composition and lighter in color (likely well oxygenated) than the sediments underneath. A similar surficial veneer of sediments was observed at a few other locations, most notably at the locations sampled around high water or low water when the fluff layer is expected to be at its maximum thickness. Although the erodibility associated with this surficial veneer is unknown, its prevalence around slack water may be indicative of the fluff layer.

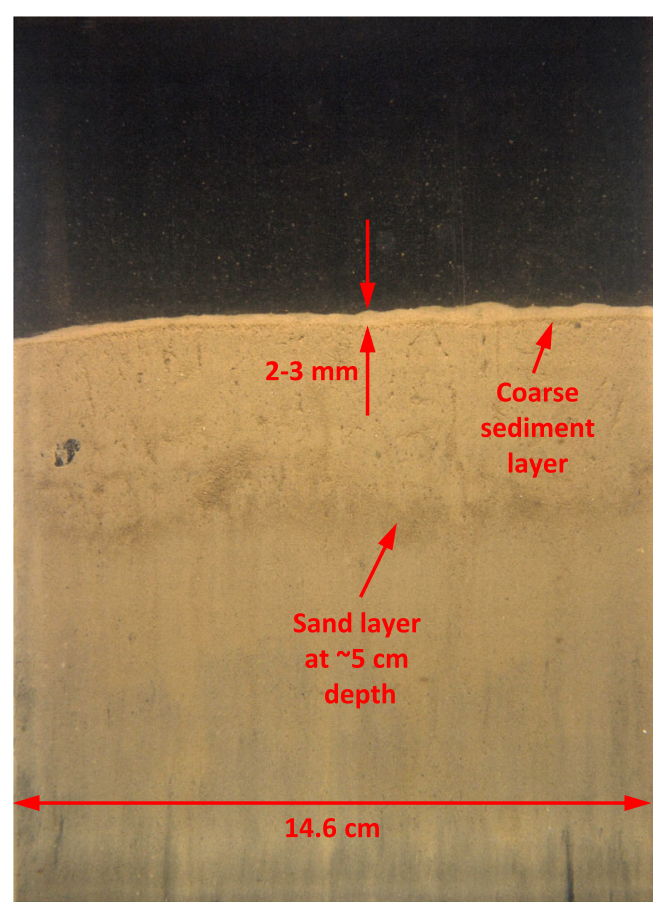

Fig. 13 Sediment depth-profile image (captured near station 1 shown in Fig. 1) during a SPI survey in the LPR
- Numerical modeling (indirect evidence)-The entrainment flux method presented herein was developed in the context of a numerical sediment transport model application of the LPR (unpublished work). This model, which includes a fluff layer parameterized using the entrainment flux method, has been calibrated and applied over various time scales ranging from tidal to decadal, and covering the full range of river flows in the LPR. A sensitivity simulation with this model without including a fluff layer allows for an assessment of the importance of the fluff layer and also provides indirect support for the presence of the fluff layer-see also our next argument. The results of this sensitivity simulation showed that estuarine sediment dynamics such as tidal asymmetry in SSC, ETM formation, net up-estuary SS flux, net sedimentation, etc. during below-average flow conditions were not well reproduced. Only the inclusion of the fluff layer enabled the model to reproduce these SS dynamics. This comparison of model results, with and without considering a fluff layer, provides another line of evidence to support the existence of the fluff layer in the LPR.

- Estuary-scale processes (indirect evidence)-Theoretical arguments building on the findings of others also support the notion of an easily erodible fluff layer overlying less erodible strata. The net transport of fine sediments against the residual (river) flow during periods of low to moderate river flow and typical tidal conditions is governed by estuarine circulation and tidal asymmetry (in peak currents as well as slack-water duration). The latter process is also applicable up-estuary of the salt front (Friedrichs 2010; Dronkers 2005). In case of fine sediments limited by availability in the bed (starved-bed conditions), net sediment transport occurs due to scour lag and settling lag, induced around slack water (De Swart and Zimmerman 2009; Van Straaten and Kuenen 1957). These lag effects implicitly assume the formation (via deposition) and erosion of an easily erodible layer of sediment over intra-tidal time scales on an otherwise more or less stable bed. Thus, empirical observations and the analytical formulations of net sediment transport in various tidal and estuarine systems reported upon by various authors also rely upon the notion of an easily erodible layer overlying less erodible strata.

In summary, several lines of evidence support the presence of a fluff layer in the LPR. The arguments range from direct measurements (such as Gust microcosm, and Sedflume), indirect or inferred evidence (SSC data, SPI data, and numerical model application), and theoretical expectations. In addition, the results of numerical model sensitivity simulations with and without the fluff layer indicate the sediment fate and transport processes influenced by the presence of the fluff layer, and the relevance of the fluff layer to such fate and transport studies. 
Open Access This article is distributed under the terms of the Creative Commons Attribution 4.0 International License (http:// creativecommons.org/licenses/by/4.0/), which permits unrestricted use, distribution, and reproduction in any medium, provided you give appropriate credit to the original author(s) and the source, provide a link to the Creative Commons license, and indicate if changes were made.

\section{References}

Amos CL, Daborn GR, Christian HA, Atkinson A, Robertson A (1992) In situ erosion measurements on fine-grained sediments from the Bay of Fundy. Mar Geol 108:175-196. doi:10.1016/00253227(92) 90171-D

Ariathurai CR, Arulanandan K (1978) Erosion rates of cohesive soils. J Hydraul Div-ASCE 104(2):279-282

Bedford KW, Onyx W, Libicki CM, Van Evra R (1987) Sediment entrainment and deposition measurements in Long Island Sound. J Hydraul Eng 113(10):1325-1342

Chant RJ, Fugate D, Garvey E (2011) The shaping of an estuarine superfund site: roles of evolving dynamics and geomorphology. Estuar Coast 34:90-105

Chesapeake Biogeochemical Associates, CBA (2006) Passaic River erosion testing and core collection: field report and data summary. Final Report to Malcolm Pirnie, Inc., White Plains, NY

Costa RG (1989) Flow-fine sediment hysteresis in sediment-stratified coastal waters. MS Thesis, University of Florida, Gainesville.

De Swart HE, Zimmerman JTF (2009) Morphodynamics of tidal inlet systems. Annu Rev Fluid Mech 41:203-229

Deines KL (1999) Backscatter estimation using broadband acoustic Doppler current profilers. In Oceans 99 MTS/IEEE Conference Proceedings, September 13-16, 1999, Seattle, WA.

Dronkers J (1985) Tide-induced residual transport of fine sediment. In: Proceedings of the Symposium on the Physics of Shallow Bays and Estuaries, Miami 1984. Springer-Verlag

Dronkers J (2005) Dynamics of coastal systems. Advanced Series on Ocean Engineering-Vol 25. World Scientific

Dyer KR (1997) Estuaries: a physical introduction, 2nd edn. Sons, John Wiley \&

El Ganaoui O, Schaaff E, Boyer P, Amielh M, Anselmetc F, Grenz C (2004) The deposition and erosion of cohesive sediments determined by a multi-class model. Estuar Coast Shelf S 60:457-475

Friedrichs CT (2010) In: Valle-Levinson A (ed) Barotropic tides in channelized estuaries. Contemporary issues in estuarine Physics. Cambridge University Press, pp 27-61

Germano \& Associates, Inc (2005) Sediment profile imaging survey of sediment and benthic habitat characteristics of the Lower Passaic River. Lower Passaic River Restoration Project, Bellevue, WA

Gust G, Mueller V (1997) Interfacial hydrodynamics and entrainment functions of currently used erosion devices. Cohesive sediments. In: Burt N, Parker WR, Watts J (eds) . John Wiley and Sons, New York, pp 149-174

HydroQual (2008) Final hydrodynamic modeling report. Lower Passaic River Restoration Project and Newark Bay Study, Mahwah, NJ

Kandiah A (1974) Fundamental aspects of surface erosion of cohesive soils. Ph.D. dissertation, Univ. of Calif., Davis.

Lerczak JA, Geyer WR, Chant RJ (2006) Mechanisms driving the timedependent salt flux in a partially stratified estuary. J Phys Oceanogr 36(12):2283-2298

Maa JP-Y, Wright LD, Lee CH, Shannon TW (1993) VIMS Sea Carousel: a field instrument for studying sediment transport. Mar Geol 115:271-287
Maa JP-Y, Sanford L, Halka JP (1998) Sediment resuspension characteristics in Baltimore Harbor, Maryland. Mar Geol 146:137-145

McNeil J, Taylor C, Lick W (1996) Measurements of erosion of undisturbed bottom sediments with depth. J Hydraul Eng-ASCE 122(6): 316-324

Mehta AJ (1991) Characterization of cohesive soil bed surface erosion, with special reference to the relationship between erosion shear strength and bed density. University of Florida, Gainesville, FL UFL/COEL/MP-91/4

Mehta AJ, Partheniades E (1982) Resuspension of deposited cohesive sediment beds. 18th International Conference on Coastal Engineering. Coastal Engineering Research Council, Cape Town, South Africa

Meselhe, EA, and Rodrigue MD (2013) Mississippi River Hydrodynamics and Delta Management Study (MRHDM): models performance assessment metrics and uncertainty analysis. Final report prepared for Louisiana Coastal Protection and Restoration Authority, Baton Rouge, LA.

Parchure TM, Mehta AJ (1985) Erosion of soft cohesive sediment deposits. J Hydraul Eng-ASCE 111(10):1308-1326

Partheniades E (1962) A study of erosion and deposition of cohesive soils in salt water. Ph.D. dissertation, Univ. of Calif., Berkeley.

Partheniades E (1965) Erosion and deposition of cohesive Soils. J Hydraul Div-ASCE 91(1):105-139

Partheniades E (2010) Cohesive sediments in open channels: properties, transport, and applications. Elsevier, New York

Piedra-Cueva I, Mory M (2000) Erosion of a deposited layer of cohesive sediment. In: McAnally WH, Mehta AJ (eds) Proceed Marine Sci, vol 3. Elsevier, pp 41-51 ISSN 1568-2692, ISBN 9780444504630

Postma H (1961) Transport and accumulation of suspended matter in the Dutch Wadden Sea. Neth J Sea Res 1:148-190

Sanford LP, Halka JP (1993) Assessing the paradigm of mutually exclusive erosion and deposition of mud, with examples from upper Chesapeake Bay. Mar Geol 114:37-57

Sanford LP, Maa JP-Y (2001) A unified erosion formulation for fine sediments. Mar Geol 179:9-23

Sanford LP, Panageotou W, Halka JP (1991) Tidal resuspension of sediments in Northern Chesapeake Bay. Mar Geol 97:87-103

Sea Engineering, Inc. (2013) Sedflume analysis data report Newark Bay, New Jersey. Prepared for U.S. Environmental Protection Agency, Santa Cruz, CA

Siegle E, Schettini CAF, Klein AHF, Toldo EE (2009) Hydrodynamics and suspended sediment transport in the Camboriu Estuary-Brazil: pre jetty conditions. Braz J Oceanogr 57(2):123-135

Sommerfield CK, Wong KC (2011) Mechanisms of sediment flux and turbidity maintenance in the Delaware Estuary. J Geophys Res 116: C01005. doi:10.1029/2010JC006462

Tolhurst TJ, Black KS, Paterson DM, Mitchener HJ, Termaat GR, Shayler SA (2000) A comparison and measurement standardisation of four in situ devices for determining the erosion shear stress of intertidal sediments. Cont Shelf Res 20:1397-1418

Tsao M, Ling X (2012) Subsampling method for robust estimation of regression models. Open J Stat 2:281-296

Van Kessel T, Winterwerp JC, Van Prooijen B, Van Ledden M, Borst W (2011) Modeling the seasonal dynamics of SPM with a simple algorithm for the buffering of fines in a sandy seabed. Cont Shelf Res 31:124-134

Van Maren DS, van Kessel T, Cronin K, Sittoni L (2015) The impact of channel deepening and dredging on estuarine sediment concentration. Cont Shelf Res 95:1-14

Van Prooijen BC, Winterwerp JC (2010) A stochastic formulation for erosion of cohesive sediments. J Geophys Res 115:C01005. doi: 10.1029/2008JC005189

Van Rijn LC (1984) Sediment transport, part II: suspended load transport. J Hydraul Eng-ASCE 110(11):1613-1641 
Van Rijn LC (1993) Principles of sediment transport in rivers, estuaries, and coastal seas. Aqua Publications, Emmeloord, The Netherlands

Van Straaten LMJU, Kuenen PHH (1957) Accumulation of fine grained sediments in the Dutch Wadden Sea. Geol Mijnb 19(329):354

deVries JW (1992) Field measurements of the erosion of cohesive sediments. J Coast Res 8(2):312-318

Wall GR, Nystrom EA, Litten S (2006) Use of an ADCP to compute suspended-sediment discharge in the tidal Hudson River. New York USGS SIR:2006-5055

Wang YH (2003) The intertidal erosion rate of cohesive sediment: a case study from Long Island Sound. Estuar Coast Shelf S 56:891-896
Winterwerp JC (2002) On the flocculation and settling velocity of estuarine mud. Cont Shelf Res 22:1339-1360

Winterwerp JC, van Kesteren WGM (2004) Introduction to the physics of cohesive sediments in the marine environment. In: Developments in sedimentology, vol 56. Elsevier, New York

Winterwerp JC, van Kesteren WGM, van Prooijen B, Jacobs W (2012) A conceptual framework for shear flow-induced erosion of soft cohesive sediment beds. J Geophys Res 117:C10020. doi:10.1029/ 2012JC008072 